\title{
Fabric Space Radiators
}
Z. I. Antoniak
J. T. Prater
W. J. Krotiuk
J. M. Bates
B. J. Webb

January 1988

Prepared for

the U.S. Air Force Weapons Laboratory/AWYS

under a Related Services Agreement

with the U.S. Department of Energy

Contract DE-AC06-76RLO 1830

Pacific Northwest Laboratory

Operated for the U.S. Department of Energy

by Battelle Memorial Institute 


\title{
DISCLAIMER
}

This report was prepared as an account of work sponsored by an agency of the United States Government. Neither the United States Government nor any agency thereof, nor Battelle Memorial Institute, nor any of their employees, makes any warranty, expressed or implied, or assumes any legal liability or responsibility for the accuracy, completeness, or usefulness of any information, apparatus, product, or process disclosed, or represents that its use would not infringe privately owned rights. Reference herein to any specific commercial procluct, process, or service by trade name, trademark, manufacturer, or othenwise, does not necessarily constitute or imply its endorsement, recommendation, or favoring by the United States Government of any agency thereof, or Battelle Memorial Institute. The views and opinions of authors expressed herein do not necessarly state or reflect those of the United States Government or any agency thereof, or Battelle Memorial Institute.

\author{
PACIFIC NORTHWEST LABORATORY \\ operated by \\ BATTELLE MEMORIAL INSTITUTE \\ for the \\ UNITED STATES DEPARTMENT OF ENERGY \\ under Contract DE-AC06-76RLO 1830
}

\begin{tabular}{|c|c|}
\hline \multicolumn{2}{|c|}{ Printed in the United States of America } \\
\hline \multirow{2}{*}{\multicolumn{2}{|c|}{$\begin{array}{l}\text { Available from } \\
\text { nal Technical Information Service }\end{array}$}} \\
\hline & \\
\hline \multirow{3}{*}{\multicolumn{2}{|c|}{$\begin{array}{c}\text { United States Department of Commerce } \\
5285 \text { Port Royal Road } \\
\text { Springfield, Virginia 22161 }\end{array}$}} \\
\hline & \\
\hline & \\
\hline \multirow{2}{*}{\multicolumn{2}{|c|}{$\begin{array}{l}\text { NTIS Price Codes } \\
\text { Microfiche A01 }\end{array}$}} \\
\hline & \\
\hline \multicolumn{2}{|c|}{ Printed Copy } \\
\hline & Price \\
\hline Pages & Codes \\
\hline $001-025$ & $\mathrm{~A} 02$ \\
\hline 026-050 & $\mathrm{A} 03$ \\
\hline 051-075 & A.04 \\
\hline $076-100$ & A05 \\
\hline $101-125$ & A06 \\
\hline $126-150$ & A07 \\
\hline $151-175$ & A08 \\
\hline $176-200$ & A09 \\
\hline $201-225$ & A010 \\
\hline 226-250 & A011 \\
\hline 251-275 & A012 \\
\hline $276-300$ & $\mathrm{~A} 013$ \\
\hline
\end{tabular}




\author{
Z. I. Antoniak \\ W. J. Krotiuk \\ B. J. Webb \\ J. T. Prater \\ J. M. Bates
}

January 1988

\author{
Prepared for \\ the U.S. Air Force Weapons Laboratory/AWYS \\ under a Related Services Agreement \\ with the U.S. Department of Energy \\ Contract D0E-ACO6-76RLO 1830
}




\section{$\underline{\text { SUMMARY }}$}

Future Air Force space missions will require thermal radiators that both survive in the hostile space environment and stow away for minimal bulk during launch. Advances in all aspects of radiator design, construction, and analysis will be necessary to enable such future missions.

Currently, the best means for obtaining high strength along with flexibility is through structures known as fabrics. Granted that these belong to some of the most ancient constructs, the development of new materials and bonding techniques has extended the application range of fabrics into areas traditionally dominated by monolithic and/or metallic structures. Possibly the most graphic example of this displacement of traditional materials, structures, and fabrication methods by novel techniques employing fabrics is seen in the use of composites for high-performance aircraft components and even sports equipment (e.g., tennis racquets). The extension of such applications into space is, therefore, viewed as a natural progression in the development of fabric structures. Given that even current spacecraft heat rejection considerations tend to dominate spacecraft design and mass, the larger and more complex designs of the future face daunting challenges in themal control. Ceramic fabrics bonded to ultra-thin metal liners (foils) have the potential of achieving radiator performance levels heretofore unattainable, and of readily matching the advances made in other branches of spacecraft design.

In this study, we have examined some of the options presented by fabrics incorporated into space radiators. For the baseline helium/xenon working fluid system, preliminary analyses indicate that either direct or secondary radiator systems should be feasible. In the direct system, the helium/xenon from the heat engine is itself the coolant, transferring heat to the fabric wall. The secondary system has another fluid, optimized for the radiator, with which the helium/xenon exchanges heat. Only the first system has been analyzed in detail here and appears to offer great promise. It would be flexible, have a low mass (about $1.0 \mathrm{~kg} / \mathrm{m}^{2}$ of projected radiator surface area), and would be inherently somewhat hardened against laser threats. Survivability against micrometeoroid punctures is a principal concern and is not easily 
achieved with a system that is subject to single point failure. Therefore, additional work is needed to incorporate system options that will harden the system. In any case, micrometeoroid armoring/redundancy would require approximately $2.4 \mathrm{~kg} / \mathrm{m}^{2}$ more mass than an unprotected radiator, for a total radiator mass of approximately $3.4 \mathrm{~kg} / \mathrm{m}^{2}$. Of itself, this is probably an acceptable mass penalty; the true problem that needs resolution is one of effectively isolating damaged panels.

Even if a pumped-10op radiator system cannot be protected against micrometeoroid punctures, it might still have a niche. For large power systems, heat pipes are hardly appropriate. Moreover, such large power systems generally have only burst power capability. For this type of power system, a lightweight, pumped-1oop system that could be stowed when not operating could well become the system of choice.

Heat pipes offer many attractive features in a space radiator role, of which the chief one is the redundancy resulting from each heat pipe being an isolated unit whose destruction need hardly affect the operation of the rest. But metal heat pipes are relatively heavy, and their fabrication is still more art than science. This study shows that both these drawbacks could be significantly decreased or entirely eliminated. Through the use of ceramic fabrics in the wick and outer (pressure containment) wall, mass can be reduced to about one-half that of metal heat pipes. An additional $2 \mathrm{~kg} / \mathrm{m}^{2}$ of armoring would provide adequate micrometeoroid puncture survivability, so that a fabric heat pipe radiator system with a potassium working fluid would have a total mass of about $8.2 \mathrm{~kg} / \mathrm{m}^{2}$ of projected area; a comparable titanium heat pipe would have a mass of about $32.0 \mathrm{~kg} / \mathrm{m}^{2}$, which is in the $20-$ to $40-\mathrm{kg} / \mathrm{m}^{2}$ range of current heat pipe designs (Dearien and Whitbeck 1987). Note that this mass is for a nonoptimized design; significant mass reduction could result from a decrease or elimination of the circumferential distributive wick. Currently, only a relative comparison of fabric versus metal pipes is meaningful. Absolute mass values can be obtained only from an experimental effort.

Although considerably heavier than a pumped-loop system, a fabric heat pipe syster could probably be implemented in the near term and would be adequate for the multikilowatt power levels anticipated for the next spacecraft 
generation. Regarding fabrication, the usual difficulties associated with wick and artery construction, and of having these components perform in a reproducible manner, can potentially be eased with the proposed ceramic wick structure bonded directly to a metallic foil liner.

In a parallel effort, various ceramic fabrics have been bonded to various metal foil liners. The results to date are encouraging, and suggest that the approach is sound. We have achieved good bonds, while retaining the desired flexibility in the sandwich. Development of optimal bonding techniques and material combinations requires additional work, but the current study provides good insight into the paths future research should take. The measured masses of fabric/braze/foil samples ranged from 0.6 to $1.3 \mathrm{~kg} / \mathrm{m}^{2}$. No attempt was made for these to be particularly lightweight, so the potential exists for additional mass reductions.

In summary, the research effort documented here indicates that both pumped loops and heat pipes constructed in ceramic fabrics stand to benefit in multiple ways. Flexibility and low mass are the main advantages exhibited by fabric radiators over conventional metal ones; other benefits are described in the body of the report. We feel that fabric radiators have intrinsic merits not possessed by any other radiator design and need to be researched further. 


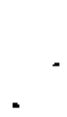

v

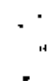




\section{ACKNOWLEDGMENTS}

This work was supported by the Air Force Weapons Laboratory, under PNL Contract 300A-12301. 



\section{CONTENTS}

SUMMARY ...........................

ACKNOWLEDGMENTS ................................ vii

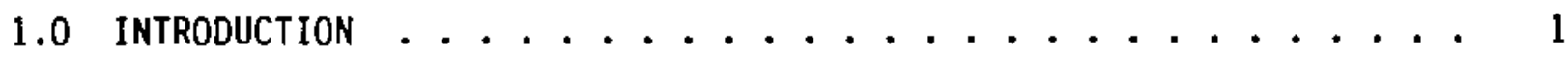

2.0 Materials StUdY ...................... 7

2.1. BACKGROUND ....................... 7

2.2. METALLIZATION/FABRICATION EXPERIMENTS ......... . . 9

2.2.1. Common Adhesive Bonding . . . . . . . . g 9

2.2.2. Braze Bonding.............. 9

2.2.3. Ceramic Adhesive Bonding . . . . . . . . 11

2.2.4. Discussion ................. 12

2.2.5. Conclusions ................. 13

2.3. RELATED EXPERIMENTS . . . . . . . . . . . . 13

2.3.1. Permeability .............. 15

2.3.2. Wetting/Wicking .......... 16

3.0 SPACE RADIATOR CONCEPTUAL DESIGN AND HEAT TRANSFER ANALYSIS . . . 19

3.1. HELIUM/XENON DIRECT PUMPED-LOOP RADIATOR . . . . . . . 19

3.2. LITHIUM SECONDARY-SYSTEM PUMPED-LOOP RADIATOR . . . . . . . 27

3.3. HEAT PIPE RADIATOR . . . . . . . . . . . 27

4.0 MICROMETEOROID ANALYSIS . . . . . . . . . . . 33

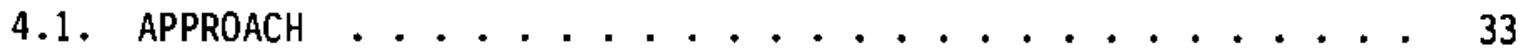

4.2. PUMPED-LOOP SURVIVABILITY CALCULATIONS ........ 39

4.3. HEAT PIPE SURVIVABILITY CALCULATIONS . . . . . . . . 45

5.0 RADIATOR OPERATION ....................... 47

5.1. STARTUP/TRANSIENTS/SHUTDOWN . . . . . . . . . 47 
5.2. SHAPE ALTERATION ................... 48

6.0 FEASIBILITY ISSUES . . . . . . . . . . . . . 49

6.1. KEY TECHNICAL ISSUES IDENTIFIED ............. 49

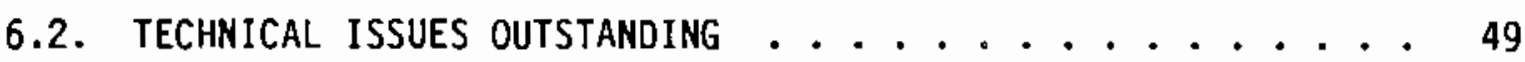

6.3 RECOMMENDED APPROACH ................... 50

7.0 CONCLUSIONS ........................... 53

8.0 REFERENCES ........................... 55

APPENDIX A - SAMPLE HEAT PIPE CODE RESULTS . . . . . . . . A. . A

APPENDIX B - SURVIVABILITY PROGRAM LISTING . . . . . . . . . B. 


\section{FIGURES}

1.1 Reference Brayton-Cycle Space Power System . . . . . . . . 3

1.2 Direct Radiator . . . . . . . . . . . . . . 4

1.3 Radiator System with Intermediate Heat Exchanger . . . . . . 4

1.4 Cross Section of a Fabric Heat Pipe . . . . . . . . . 5

2.1 Fabric Coating/Bonding Techniques ............ 10

2.2 Sample Leak Test Apparatus . . . . . . . . . . 16

2.3 Sample Leak Test Fixture . . . . . . . . . . . . 17

2.4 Wicking Heights of Standard Fabric Samples . . . . . . . . 18

3.1 Circular Direct Radiator Design . . . . . . . . . . 20

3.2 Thermal Resistance Model for Radiator Surface . . . . . . . . 21

3.3 Channel Exit Temperature For Helium/Xenon Flow ........ 22

3.4 Radiator Heat Removal Design Curve For Helium/Xenon Flow . . . . 23

3.5 Radiator Pressure Drop Oesign Curve For Helium/Xenon Flow . . . . 24

4.1 Average Cumulative Meteoroid Mass Flux for Near-Earth Orbits . . 34

4.2 Product of Earth's Gravitational Defocusing and Body Shielding

Factors, GeE, as a Function of Distance from Earth's Center ... . 36

4.3 Probability Distribution of Observed Meteoroid Velocities .... 38 


\section{$\underline{\text { TABLES }}$}

2.1 Candidate Metal Sealant Layers for Various Working Fluids . . . . 7

2.2 Ultimate Tensile Strengths of Tungsten-Coated and Uncoated Silicon Carbide Filaments at Various Temperatures . . . . . . 8

2.3 Summary of Radiator Skin Fabrication Experiments . . . . . . . . 14

3.1 Calculated Radiative Heat Transfer Coefficients with Aluminum Surface Treatment . . . . . . . . . . . . . . . 22

3.2 Design Conditions for Helium/Xenon Cases Studied . . . . . . . . 26

3.3 Heat Pipe Performance Summary . . . . . . . . . . . . . . 29

4.1 Constants for Threshold Penetration for a Monolithic Barrier at $298 \mathrm{~K}$. . . . . . . . . . . . . . . . . 37

4.2 Effects of System Reliability on Pumped-Loop Redundancy and System Mass, Case 1 [helium/xenon pumped loop, flow area $1.0 \times 10^{-3} \mathrm{~m}^{2}$, channel length $10 \mathrm{~m}$, required number of loops at end-of-life (EOL) 93, unarmored mass $=35.9 \mathrm{~kg}] \ldots . .$. . .

4.3 Effects of System Reliability on Pumped-Loop Redundancy and System Masss, Case 2 (helium/xenon pumped loop, flow area $1.0 \times 10^{-3} \mathrm{~m}^{2}$, channel length $20 \mathrm{~m}$, required number of loops at EOL 43, unarmored mass $=33.2 \mathrm{~kg}) . . . . . . . . .$.

4.4 Effects of System Reliability on Pumped-Loop Redundancy and System Mass, Case 3 (helium/xenon pumped loop, flow area $4.91 \times 10^{-4} \mathrm{~m}^{2}$, channel length $10 \mathrm{~m}$, required number of loops at EOL 125, unamored mass $=32.9 \mathrm{~kg}$ ) . . . . . . . . . . .

4.5 Effects of System Reljability on Pumped-Loop Redundancy and System Mass, fase 4 (helium/xenon pumped loop, flow area $4.91 \times 10^{-3} \mathrm{~m}^{2}$, channel length $20 \mathrm{~m}$, required number of loops at EOL 59, unarmored mass $=31.1 \mathrm{~kg}) \ldots . . . . . . . . .$.

4.6 Effects of System Reliability on Pumped-Loop Redundancy and System Mass, Case 5 (helium/xenon pumped loop, flow area $7.85 \times 10^{-5} \mathrm{~m}^{2}$, channel length $10 \mathrm{~m}$, required number of loops at EOL 291, unamored mass $=29.9 \mathrm{~kg}) . . . . . . . . .$. .

4.7 Effects of System Reliability on Pumped-Loop Redundancy and System Mass, fase 6 (helium/xenon pumped loop, flow area $7.85 \times 10^{-5} \mathrm{~m}^{2}$, channel length $20 \mathrm{~m}$, required number of loops at EOL 134 unarmored mass $=27.6 \mathrm{~kg}$ ) . . . . . . . . . . . 
4.8 System Mass Estimate of Helium/Xenon Pumped Loop with Three Pumped Loops Sharing a Common Isolation Valve (system reliability 0.999)

4.9 System Mass Estimate for Postulated Heat Pipe Systems as a Function of Structural Material (system reliability 0.99 , operational lifetime 10 years $) \ldots \ldots . \ldots 45$

6.1 Key Technical Issues . . . . . . . . . . . . 49

6.2 Approaches for Enhancing Survivability Against Micrometeoroid Punctures ................... 51 

FABRIC SPACE RADIATORS

\section{$1.0 \quad$ INTRODUCTION}

Numerous radiator types have been proposed for rejecting heat from the large power plants envisioned for future spacecraft. Although these radiators are in various stages of study and development, some of which are well along in providing definitive data, currently no radiator design exists that is capable of simultaneously meeting all design criteria. For Air Force missions, the most stringent criteria relate to size, survivability, and weight. Preliminary information indicates that these may be met by a novel class of radiators, based on fabric materials that have been treated for compatibility with the working fluid and for enhanced radiative characteristics (Webb and Antoniak 1986).

A study was recently initiated at the Pacific Northwest Laboratory (PNL) to analytically and experimentally consider design and construction of fabric material radiators. The full range of radiator types, from thin panels to single-phase pumped loops with extended surfaces (fins) to heat pipes, is under investigation. The approach taken is straightforward: an experimental effort seeks to find suitable fabric materials and coating/sealing techniques that will prevent working fluid loss while maintaining structural integrity and flexibility.

The latter feature is especially desirable, as payload volume on launch vehicles is always restricted. A flexible radiator also offers benefits such as adaptability to a variable heat load, and could be retracted for enhanced survivability. Such features have already been incorporated into flexible metal heat pipes (Merrigan et al. 1984; Ponnappan, Beam, and Mahefkey 1986) and other radiators (Chow and Mahefkey 1986), but it is not clear at this time if these are truly viable. A fabric/metal-foil radiator construction is inherently highly compliant; it is felt that the compliance can largely be retained in layering and/or metallizing the base fabric during radiator construction. Depending on the fabric selected, optical properties may or may not require enhancement (Covington and Sawko 1986). 
The second part of this study is concerned with resolving design issues and comparing fabric and other radiator types. To this end, the ATHENA code developed at Idaho National Engineering Laboratory is being used in the design, optimization, and system analysis of various space radiators. Systems with and without heat exchangers are being considered. Meanwhile, the performance of fabric heat pipes is being studied with a small code created at Los ATamos National Laboratory (LANL).

The Air Force Weapons Laboratory (AFWL) selected a closed Brayton-cycle space power system for analysis (see figure 1.1). The working fluid is a helium/xenon mixture, requiring approximately $80 \mathrm{kWt}$ to be rejected to space to produce $30 \mathrm{kWe}$ net power. With inlet and out let temperatures of $575 \mathrm{~K}$ $\left(575^{\circ} \mathrm{F}\right)$ and $367 \mathrm{~K}\left(200^{\circ} \mathrm{F}\right)$ respectively, the temperature difference across the radiator becomes a fairly severe $208 \mathrm{~K}$. This Brayton system is similar to ones proposed earlier, and the usual considerations regarding the optimal characteristics of a working fluid mixture apply (Mock 1977).

Hand calculations were performed here to scope the radiator size and perfornance. Assuming a linear axial temperature profile, the effective radiator temperature is $452 \mathrm{~K}$. If the emittance-transmittance-view factor product is taken as 1.0 , the minimal radiator surface area needed is $33.9 \mathrm{~m}^{2}$. A more realistic radiator size of $50 \mathrm{~m}^{2}$ might consist of 10 thin rectangutar panels (see Figure 1.2).

Additional calculations indicated that there was no clear-cut advantage evident for a radiator system directly coupled to a Brayton heat engine with a helium/xenon working fluid, compared to the same engine rejecting heat across an intermediate heat exchanger and, thence, to a radiator with a liquid metal fluid. The simplicity of the first system (see Figure 1.2) is obtained at the price of relatively poor convective heat transfer and attendant high temperature gradients.

Survivability (Tilton and Chow 1986), including leak detection and isolation of damaged radiator sections, is also a major issue. The liquid-metal radiator system (see Figure 1.3) ameliorates such concerns to an extent. 
' $\omega$

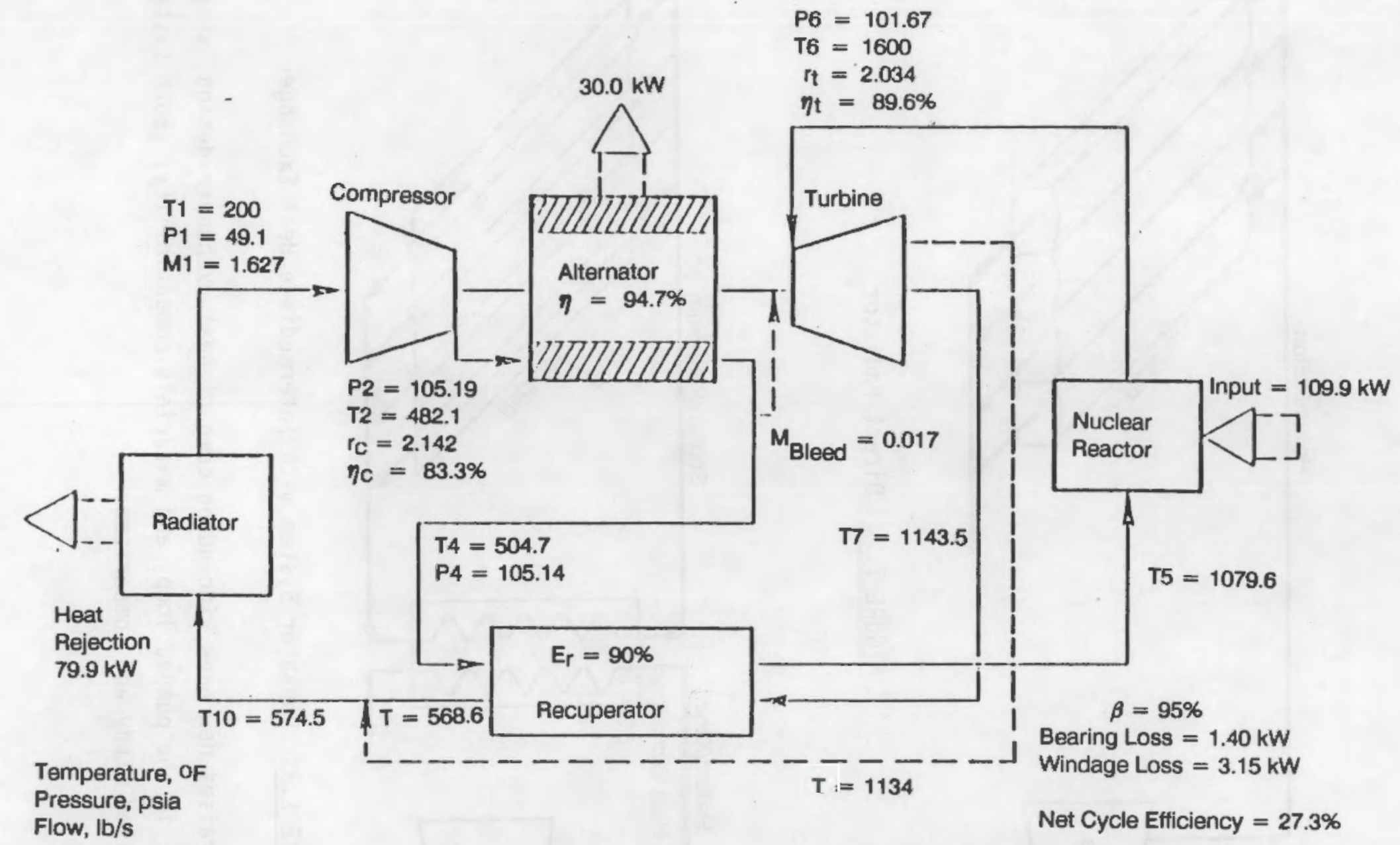

FIGURE 1.1. Reference Brayton-Cycle Space Power System 


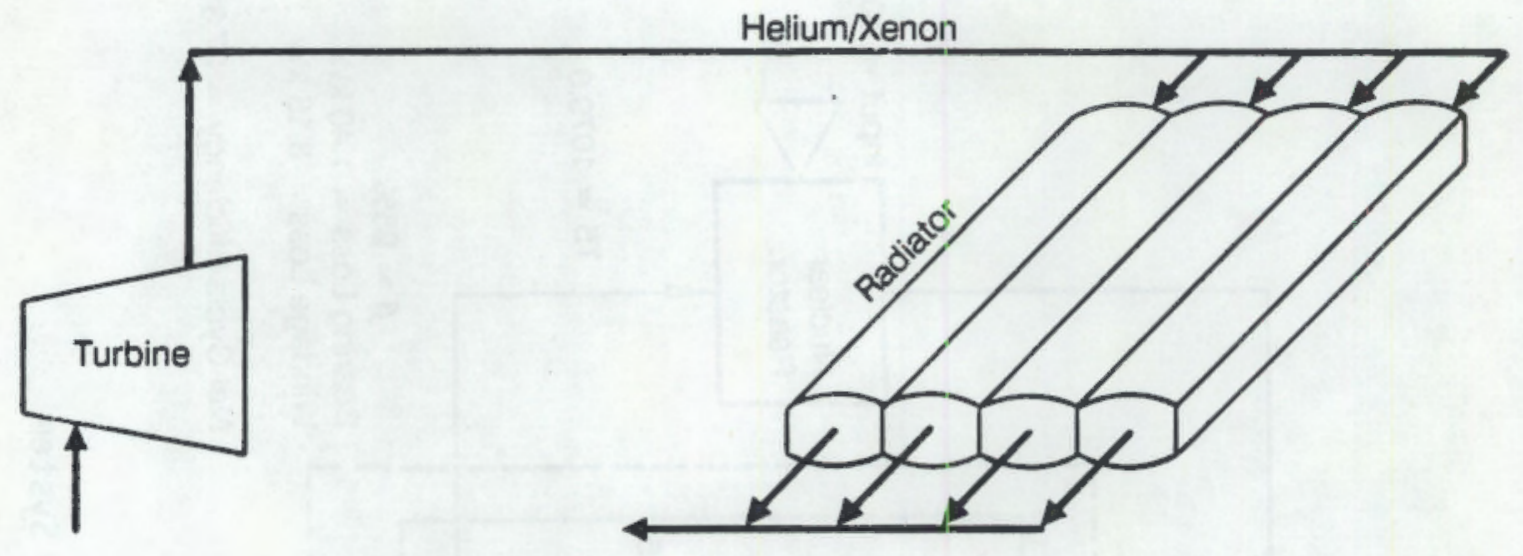

FIGURE 1.2. Direct Radiator

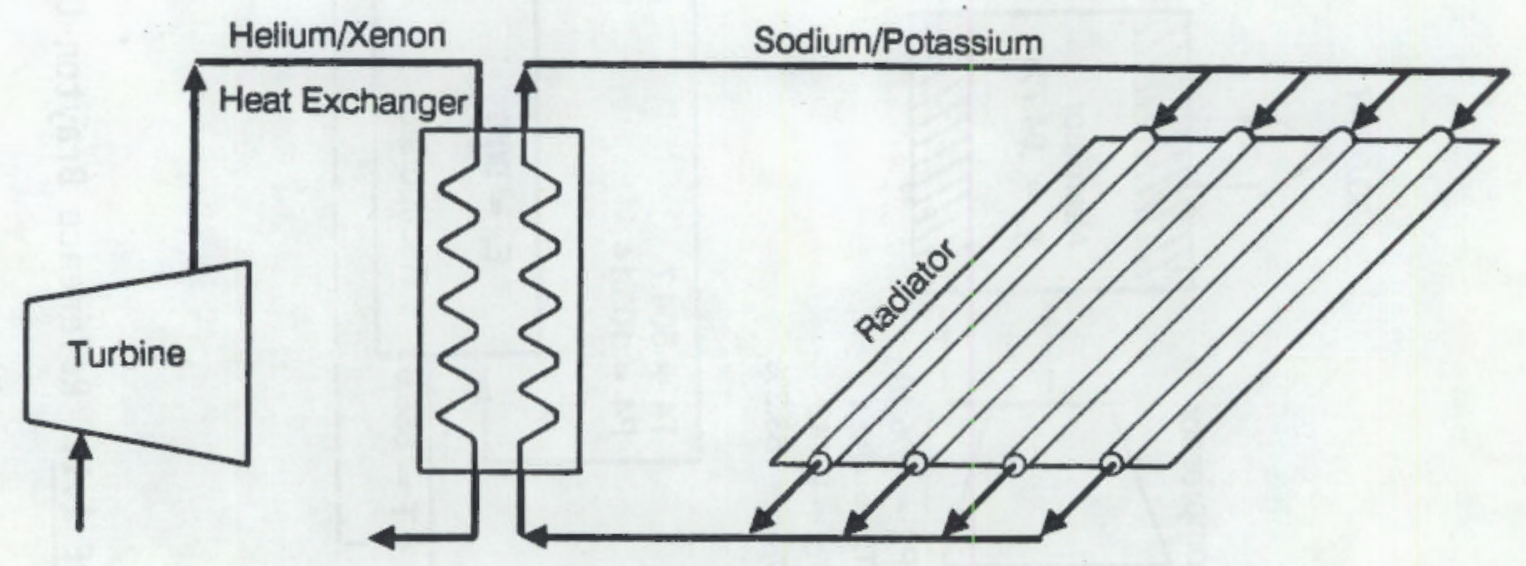

FIGURE 1.3. Radiator System with Intermediate Heat Exchanger

However, it raises new ones, including compact heat exchanger design, singlepoint failure in the pumped loop, and materials compatibility. Both systems require detailed study and comparison. 
One more radiator design was considered. A fabric heat pipe radiator has been conceived that uses technology similar to that of the pumped loops, in a sandwich construction (see Figure 1.4). Although ceramic fiber wicks have received consideration in the past (Dunn and Reay 1982, pp. 95, 144-146; Brennan and Kroliczek 1979, Vol. 1, p. 283), their flexibility was a problem. Here, we propose to take full advantage of this flexibility and ensure good contact with the liner by bonding. Again, detailed study and comparison against existing heat pipe designs are necessary to ascertain the value of this novel design.

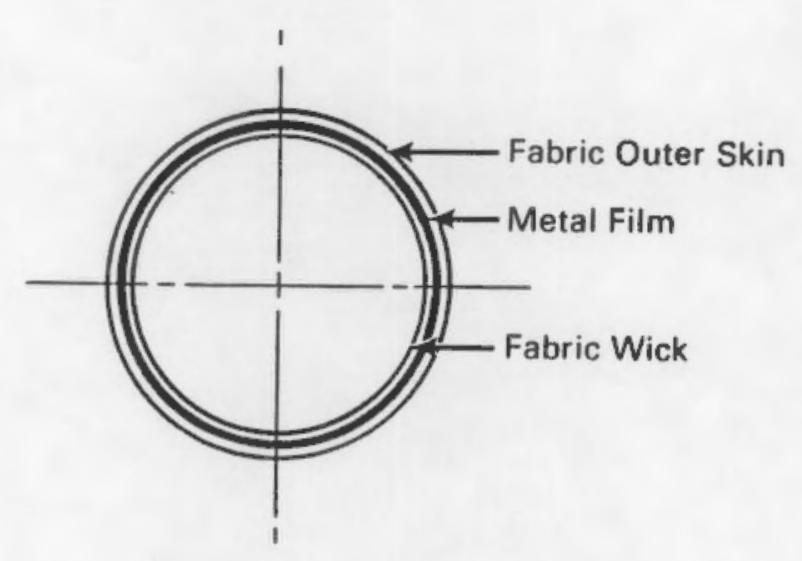

FIGURE 1.4. Cross Section of a Fabric Heat Pipe 



\subsection{MATERIALS STUDY}

In this section, the experiments and tests conducted on several alternative fibers are described. A literature search disclosed that ceramic fibers offered the best combination of high-temperature properties suitable for a fabric radiator (Tai-il Mah et al. 1987; Weeton, Peters, and Thomas 1987).

\subsection{BACKGROUND}

For this study, candidate ceramic fabrics were selected based on commercial availability and fiber flexibility. Four fabric compositions were chosen for study: silica, silicon carbide, aluminoborosilicate, and graphite. To date, no consideration of the type of weave has been attempted, although the selection is almost limitless. It is felt that this selection would best be made later in conjunction with overall design criteria.

The selection of the metal layer was dominated by the need for chemical compatibility with the working fluid. Weight was a secondary consideration. Three working fluids were considered: helium/xenon, sodium/ potassium, and lithium. The respective candidate materials chosen for the different working fluids are listed in Table 2.1.

Compatibility with the space environment, notably atomic oxygen, is also required of the different materials. However, thin coatings of silicon, aluminum, or chromium could be applied to vulnerable materials (e.g., graphite fibers) to provide adequate protection without significantly degrading their mechanical properties.

It is envisioned that the fabric radiator will consist of two primary constituents: an outer ceramic fabric to provide structural strength and

\section{TABLE 2.1. Candidate Metal Sealant Layers for Various Working Fluids}

Working Fluid
Helium/xenon
Sodium/potassium
Lithium

Candidate Metal Layer

Aluminum, titanium, nickel

Austenitic steel, molybdenum

Titanium, molybdenum 
integrity (see Table 2.2 for representative strength values, which are considerably higher than those for monolithic metals, especially when the comparison includes density), and an inner metallic liner to contain the working fluid. The most feasible approach identified to date appears to be the separate fabrication of the fabric skeleton and the metal foil liner, followed by an insertion and joining process. However, the direct application of the metal layer to a preformed fabric shell is also being considered.

Thermal properties of the fabric material samples were not measured in this study. However, thermal conductivity values are frequently available from the manufacturer. Some difficulty arises in interpreting such values; often it is unclear if the reported thermal conductivity is a true conductivity along the fibers, or if it also includes thermal radiation (preliminarily, the latter conclusion appears the more likely).

Radiative properties of various fabrics reported recently (Covington and Sawko 1986) are consistent with some unreported measurements made at PNL several years ago. In general, one can conclude that the intrinsic properties are not optimal. Two methods of enhancing the radiative heat transfer to space suggest themselves: coating the fabric fibers, or opening the weave to permit

TABLE 2.2. U1timate Tensile Strengths of Tungsten-Coated and Uncoated Silicon Carbide Filaments at Various Temperatures (from Weeton, Peters, and Thomas 1987, p. 5-12)

\begin{tabular}{|c|c|c|c|c|c|c|}
\hline \multicolumn{2}{|c|}{ Temperature, } & \multicolumn{2}{|c|}{$\underset{\text { (coated) }}{\operatorname{UTS}^{(a)}(b)}$} & \multicolumn{2}{|c|}{$\begin{array}{c}\text { UTS } \\
\text { (uncoated) }\end{array}$} & \multirow{2}{*}{$\sigma / \sigma_{0}$} \\
\hline${ }^{\circ} \mathrm{C}$ & ${ }^{\circ} \mathrm{F}$ & $\mathrm{GPa}$ & $\underline{k s i}$ & $\mathrm{GPa}$ & ksi & \\
\hline R.T. & R.T. & 1.835 & 266 & 2.828 & 410 & 0.649 \\
\hline 800 & 1470 & 1.648 & 239 & 2.359 & 342 & 0.699 \\
\hline 1000 & 1830 & 1.531 & 222 & 2.083 & 302 & 0.735 \\
\hline 1200 & 2190 & 1.414 & 205 & 1.883 & 273 & 0.751 \\
\hline 1400 & 2550 & 1.083 & 157 & 1.359 & 197 & 0.797 \\
\hline 1600 & 2910 & 0.855 & 124 & 1.062 & 154 & 0.805 \\
\hline
\end{tabular}

(a) Mean ultimate tensile strength

(b) Coating thickness, $12.7 \mu \mathrm{m}$ (0.0005 in.) 
the impermeable liner to directly view space plus radiate via several bounces from the very reflective fabric. We believe that, alone or in combination, these methods will achieve an effective fabric radiator emittance rivaling that of surface-treated metal heat pipes, i.e., about 0.6 to 0.8 .

\subsection{METALLIZATION/FABRICATION EXPERIMENTS}

Extensive bonding of the metal layer to the fabric does not appear to be a critical concern. In fact, for a radiator application the bond can be quite tenuous, or even nonexistent, because the internal pressure of the system will press the metal layer firmly against the surrounding fabric upon deployment. In terms of bonding, there appears to be a tradeoff between an intimate bonding, which tends to reduce overall flexibility of the sandwich, and a looser attachment, such as one that provides only a few contact points, which permits the formation of fewer but sharper creases in the metallic layer when the composite is flexed. Sharp creasing of the metal layer is felt to be detrimental because highly worked regions would be expected to develop pinhole leaks first.

\subsubsection{Common Adhesive Bonding}

A number of sandwiching experiments have been performed (see Figure 2.1). Adhesive bonding of thin metal foils to ceramic fabrics has been found to work extremely well; this technique maintains flexibility while providing an impermeable barrier to the working fluid. The best results are obtained when care is taken to minimize the filling of the interstices in the fabric weave by the adhesive. Silicone adhesive appears to represent a plausible adhesive for use in the helium/xenon system where operating temperatures will be below $600 \mathrm{~K}$. Silicone compounds are stable in space environments (National Aeronautics and Space Administration 1985) and can be used continuously at temperatures up to $600 \mathrm{~K}$. An abundance of other bonding agents (for example, paraffin) could be used to provide an interim bond that would be present for deployment but then rapidly disappear.

\subsubsection{Braze Bonding}

For liquid-metal cooling systems where high temperatures are required, other approaches have been explored, including brazing of foils to metallized fabrics and using ceramic adhesives. Preliminary brazing experiments have 


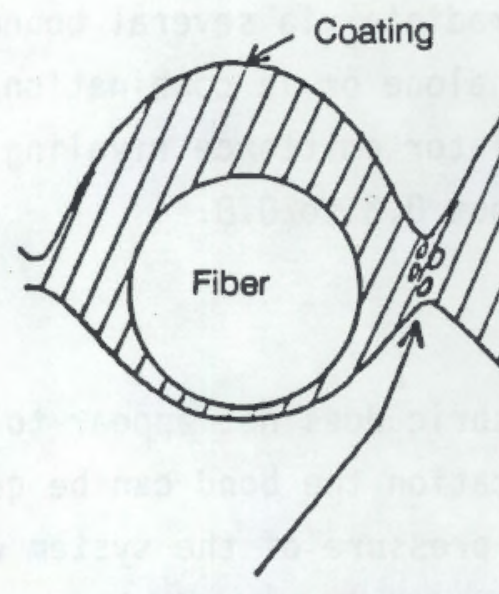

Mechanically Weak

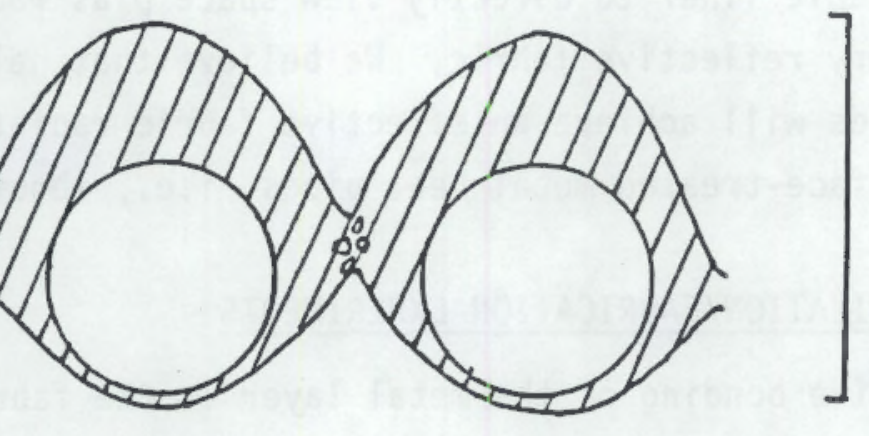

d

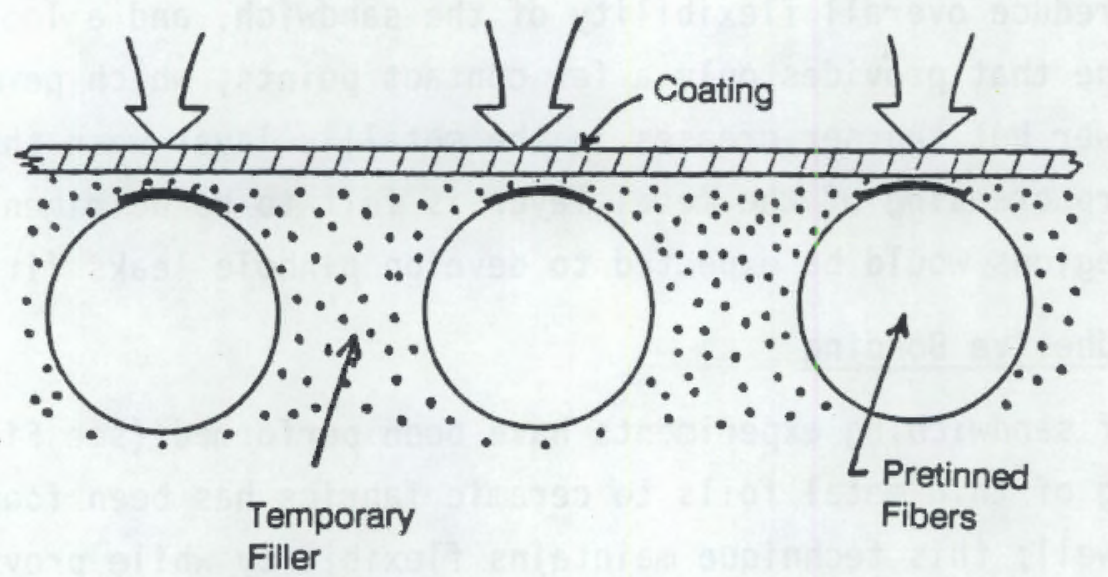

Material

FIGURE 2.1. Fabric Coating/Bonding Techniques

been encouraging. Fabrics have been successfully metallized using both electroless deposition (nickel) techniques and physical vapor deposition (titanium). In both cases the metallization left the fabric with its original flexibility. Following metallization, several brazing experiments were performed to try to bond the fabrics to steel, titanium, and molybdenum foils. In general, significant reductions in flexibility of the sandwiches were experienced. In cases where the fabric was completely coated with metal (e.g., electroless deposited nicke1), the braze sometimes wetted the entire fabric, which produced a very rigid composite sheet. However, if this could be avoided, 
some flexibility could be retained. For example, a nickel-coated siliconcarbide fabric was successfully brazed to a $25-\mu \mathrm{m}$ molybdenum foil such that it could be wrapped around a $3-\mathrm{cm}$ mandrel with no visible distress.

By far, the best brazing results were obtained when 225- $\mu m$ iron wires were woven into nonmetallized ceramic fabrics to act as the points of attachment between the fabric and the foil. In this manner an excellent bond could be obtained between the fabric and the foil, and the intermittent nature of the bonding permitted excellent flexibility. For example, using wires spaced about $2 \mathrm{~cm}$ apart, an aluminoborosilicate fabric was bonded to a 25- $\mu \mathrm{m}$ steel foil and then repeatedly bent over a $1-\mathrm{cm}$ mandrel. This is roughly equivalent to the performance of the adhesively-bonded sandwiches and yet would be applicable to much higher temperatures (about $1200 \mathrm{~K}$ ).

\subsubsection{Ceramic Adhesive Bonding}

As an alternative to brazing, several commercially-available aluminaand silica-based ceramic adhesives, rated for temperatures up to about $2000 \mathrm{~K}$, were also examined. When these were applied as a continuous bond layer, extremely rigid composites were produced. Although a strong bond developed between the fabric and the foil, the bond layer prevented any sliding between threads in the fabric. Thus, the fabric lost its original flexibility. The flexibility of the ceramically-bonded sandwiches was improved markedly when the bonding was reduced to a set of discrete points or islands. This provided a connected network of unbonded fabric between the joined areas, which accommodated the strains needed to provide maximum flexibility. Unfortunately, the ceramic adhesive was found to be very brittle, and the islands of adhesive gradually disintegrated with continued flexing of the fabric. Thus, the ceramic adhesives would be appropriate only when a limited amount of redeployment was anticipated.

A gas permeability experiment was performed to test whether these sandwich materials could remain gas impermeable following modest flexing. A titanium foil, which was adhesively bonded to an aluminoborosilicate fabric, was tested before and after being randomly wrapped around a 1.3-cm-diameter mandrel 50 times. Leak rates below the sensitivity limits of the apparatus (10 to $11 \mathrm{std} \mathrm{cc} / \mathrm{s} \mathrm{cm}^{2}$ ) were observed in both cases for a pressure drop of 
3 atm across the sample, indicating that the sandwich materials tested are capable of maintaining their integrity after modest flexing.

\subsubsection{Discussion}

The intent of this study was to demonstrate the feasibility of incorporating ceramic fabrics into space-based radiators as the structural component and, thus, present the option for providing future radiator designs with exceptional flexibility and weight savings. A preliminary review identified combinations of commercially-available materials that appear to satisfy the major criteria, notably chemical compatibility with the working fluids and low mass. By using thin metal foils backed with ceramic fabrics, an extremely durable, gas impermeable skin appears possible. Fabrication of several different candidate materials proceeded without difficulty. The relative merits of the various schemes are now being evaluated in terms of mechanical durability and thermal transport behavior.

Preliminary experiments indicate that foil thicknesses will have to be kept below about $50 \mu \mathrm{m}$ to retain good flexibility of the sandwich material, e.g., to permit wrapping around a $1-\mathrm{cm}$ mandrel. This foil thickness limitation does pose some concern for the liquid-metal radiators where surface corrosion rates of as much as $5 \mu \mathrm{m} / \mathrm{yr}$ may be experienced. Over the proposed 7to 10-year life of the power plant, a single foil layer may prove to be too thin. However, a multilayered ply containing several $50-\mu \mathrm{n}$ foil layers should be able to provide adequate thickness, strength, and flexibility.

Metallization of the fabrics has proven to be quite simple, effective, and innocuous. This not only increases the number of bonding options available, but it also suggests that thermal transport properties of the fabrics could easily be modified with surface coatings. There is clearly a penalty to be paid in a space-based radiator system that incorporates a thermal insulator in its outer skin. However, radiation out through the open weave of the fabric and conductivity through the fabric, which could be enhanced by metallization of the ceramic fabric, will decrease this penalty.

Many practical matters associated with the design and assembly of a spacebased fabric radiator have not yet been addressed. To date, no materials issues have emerged that would appear insurmountable. For example, a major 
concern might be whether the consolidation techniques used in the current study might be adapted to the manufacture of a complex system such as a radiator. The concept of fabricating the fabric skeleton and the metal foil liner separately and then bonding the two to form the final structure could prove to be extremely difficult in practice. Ultimately, it might be necessary to develop methods for directly depositing the metal layer onto the preformed fabric shell. The challenge would be to develop techniques that would permit the deposition of a thin, defect-free coating over the rough, discontinuous fabric surfaces. This could probably be accomplished using techniques such as bias sputtering that are capable of preparing defect-free coatings. By temporarily filling the interstitial gaps of the fabric with a material that could later be removed, it should be possible to develop an in situ deposition process. Thus, preliminary results to date suggest that ceramic fabrics could be effectively incorporated into space-based radiators to permit the construction of an extremely lightweight, deployable systen.

\subsubsection{Conclusions}

Preliminary studies suggest that ceramic fabrics can be combined with thin metal layers to produce gas impermeable sandwiches with exceptional flexibility and durability. Use of this material as the skin of a space-based radiator would permit the construction of extremely lightweight systems that could be easily stowed for launch. Candidate material combinations have been identified that could be used in conjunction with different working fluids (helium/xenon, sodium/potassium, lithium) at temperatures up to at least $1200 \mathrm{~K}$ (see Table 2.3).

\subsection{RELATED EXPERIMENTS}

Initially, a test series for all developed samples was planned that could incorporate tests for permeability, leak detection and survivability, thermal properties, and wetting/wicking characterization. Because of various constraints for the current year's effort, sample testing was limited to permeability and simple flexibility tests on a limited number of samples. Test conditions were simplified to ambient temperature, as compared to a 
TABLE 2.3. Summary of Radiator Skin Fabrication Experiments

\begin{tabular}{|c|c|c|c|c|}
\hline Process & $\begin{array}{c}\text { Materials } \\
\text { Fabric/Bond/Foil (Thickness, w) }\end{array}$ & $\begin{array}{l}\text { Total Skin } \\
\text { (a) } \mathrm{kg} / \mathrm{m}^{2}\end{array}$ & $\begin{array}{c}\text { Maximum } \\
\text { Tenperature, } k \\
\end{array}$ & Coments \\
\hline \multirow{5}{*}{$\begin{array}{l}\text { Adhes ive } \\
\text { bonding }\end{array}$} & $\mathrm{Al}_{2} \mathrm{O}_{3} \bullet_{2} \mathrm{~B}_{3} \cdot \mathrm{SiO}_{2} / \mathrm{paraff} \mathrm{in} / \mathrm{Al}(2 \mathrm{~S})$ & 6.6 & 460 & Very good flexibility and bonding \\
\hline & $\mathrm{Al}_{2} \mathrm{O}_{3} \bullet_{2} \mathrm{~B}_{3} \cdot \mathrm{SiO} \mathrm{O}_{2} / \mathrm{RTV} / \mathrm{Al}(25) \mathrm{SiC}$ graphite & --- & 660 & Very good flexibility and bonding \\
\hline & $\mathrm{sic}$ & 5.4 & & \\
\hline & graphito & 0.4 & & \\
\hline & $\mathrm{Al}_{2} \mathrm{O}_{3} \cdot \mathrm{B}_{2} \mathrm{O}_{3} \cdot \mathrm{SiO} / \mathrm{RTV} / \mathrm{Ti}(25)$ & $\cdots$ & 608 & Sone flexibility, good bond \\
\hline \multirow{4}{*}{$\begin{array}{l}\text { Braze } \\
\text { bonding }\end{array}$} & Ni netallized $\mathrm{Al}_{2} \mathrm{O}_{3} \bullet_{2} \mathrm{~B}_{2} \mathrm{O}_{3} \cdot \mathrm{SiO}_{2} /$ quick silver/steel (25) & -- & 896 & Some flexibility, good bond \\
\hline & $\mathrm{Ni}$ netallized $\mathrm{Al}_{2} \mathrm{O}_{3} \bullet_{2} \mathrm{~B}_{2} \mathrm{O}_{3} \cdot \mathrm{SiO}_{2} /$ cusil (63)/Ti & $1.3^{(0)}$ & 990 & Liaited flexibility, good bond \\
\hline & $\mathrm{Ti}$ motallized $\mathrm{Al}_{2} \mathrm{O}_{3} \bullet_{2} \mathrm{~B}_{3} \mathrm{O}_{3} \cdot \mathrm{SiO}_{2} / \mathrm{Pacusi}$ (25)/Wo(25) & -- & 1200 & Poorly bonded \\
\hline & $\mathrm{Al}_{2} \mathrm{O}_{3}{ }^{\circ} \mathrm{B}_{2} \mathrm{O}_{3} * \mathrm{SiO}_{2}$ with steel wires/Pacusil (25)/steel (25) & 1.1 & 1200 & Excollent flexibility and bonding \\
\hline $\begin{array}{l}\text { Ceranic } \\
\text { adhesive }\end{array}$ & $\mathrm{Al}_{2} \mathrm{O}_{3} \bullet_{2} \mathrm{~B}_{3} \mathrm{O}_{3} \cdot \mathrm{SiO}_{2} / \mathrm{silica-}$ or alunina-based adhesive/ $\mathrm{Mo}(25)$ & $\cdots$ & 1560 & $\begin{array}{l}\text { Linited to good flexibility } \\
\text { with poor bending }\end{array}$ \\
\hline $\begin{array}{l}\text { Wetallization } \\
\text { close-out }\end{array}$ & $\mathrm{Ti}(76)$ sputtered onto $\mathrm{SiO}_{2}$ fabric & --- & 1500 & $\begin{array}{l}\text { Sone pin holes present, } \\
\text { some flexibility }\end{array}$ \\
\hline
\end{tabular}

(a) Not optinized in any manner.

(b) Braze material mass was $0.6 \mathrm{~kg} / \mathrm{n}^{2}$ of this total. 
radiator design figure of $575 \mathrm{~K}\left(575^{\circ} \mathrm{F}\right)$. However, the radiator design condition was used to design and fabricate the leak test fixture such that should the test program be extended, the existing test fixture is usable. Some wicking tests were also performed.

\subsubsection{Permeability}

As a first test of radiator fabric sample permeability, the leak rate of helium through a small sample subjected to an approximate $345 \mathrm{kPa}$ (50 psia) pressure differential was measured. Leak rates of helium were measured using a helium "sniffer" unit mounted as part of vacuum pump system. The test fixture (see figures 2.2 and 2.3) provided a small helium reservoir on the metallized side of the sample. The opposite side of the sample holder was connected to the vacuum system and subjected to "hard" vacuum conditions. Any leakage across the metal foil/fabric sample would be noted by the helium sniffer unit in the vacuum system exhaust.

The test fixture was originally designed to make use of a standard large male, large female tongue-and-groove flange set, although the fixture was ultimately fabricated from carbon-steel round bar stock. The $3.51-\mathrm{cm}$ (1.38-in.) inside diameter of the 1-1/4-in. sch. 40 pipe selected yields a minimum $9.65 \mathrm{~cm}^{2}$ (1.50 in.2) of exposed sample surface when the test sample is mounted between the mating flange surfaces. The room-temperature vulcanizing (RTV) sealant was used to form leak-tight seals of the sample on both the male and female flange faces. A soft rubber 0 -ring was fitted on the outside of the tongue-and-groove flange seal to preclude leakage of outside air into the test fixture assembly. The threaded pipe construction of the helium reservoir allowed access to the assembled sample/flange set such that vacuum grease could to applied at the sample/flange interfaces in the event additional seal leaks were found.

Initial leak tests were performed on the test fixture using a "dummy" sample fabricated from $0.127-\mathrm{mm}(0.005-\mathrm{in}$.) brass shim stock to ensure that no unexpected leakage paths were present. The test fixture was found to be leak-tight. Further testing was performed on metal foil samples before and after several cycles of bending the samples around a 1.3-cm $(0.5-$ in.) diameter 


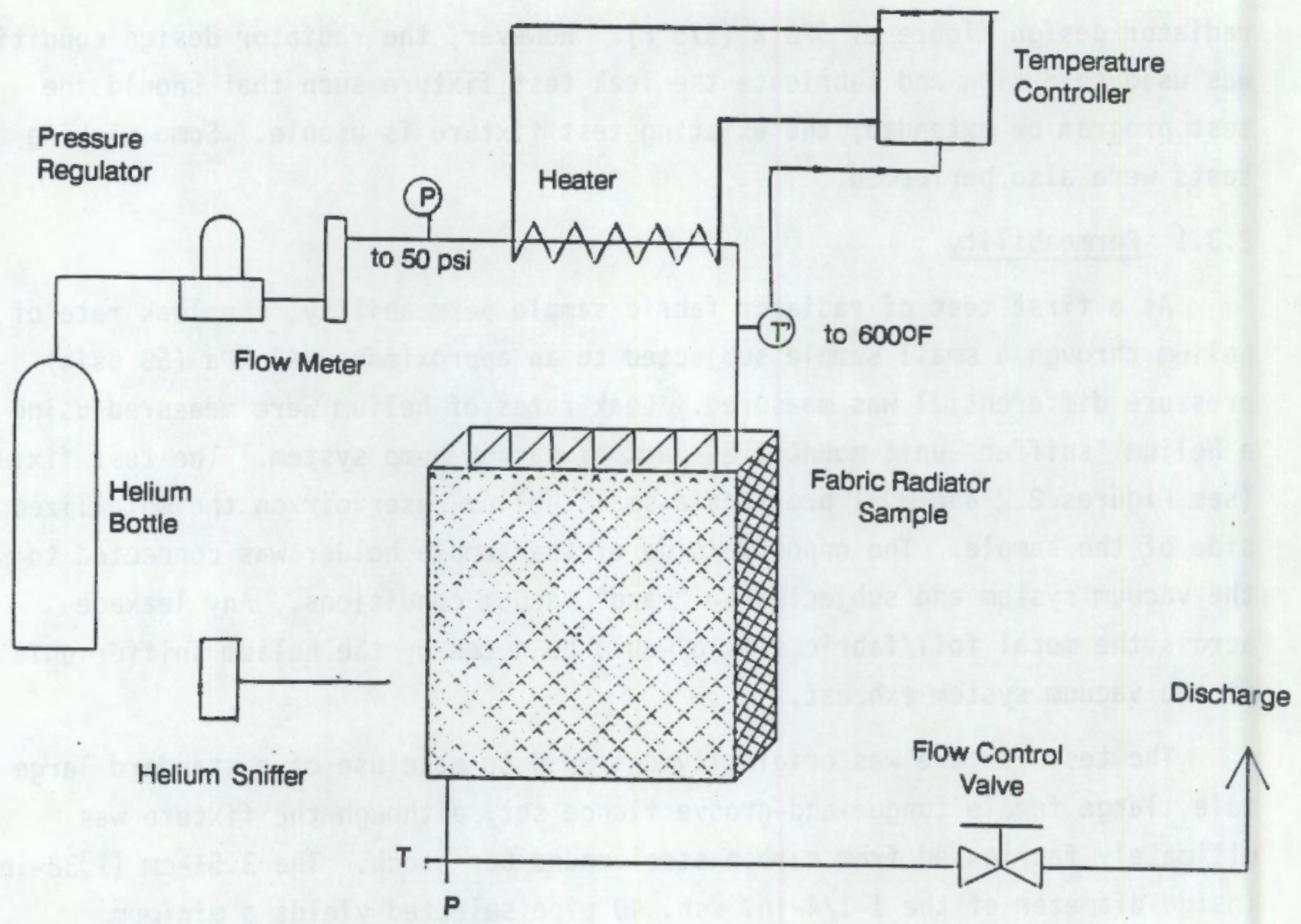

FIGURE 2.2. Sample Leak Test Apparatus

mandrel. The bending was intended as a simple simulation of the flexing that would be experienced by a fabric radiator during packaging and deployment/ retraction operations.

\subsubsection{Wetting/Wicking}

For a heat pipe to perform well, the working fluid must wet the wick and container wall (Dunn and Reay 1982, p. 92; Chi 1976, p. 36). A simple wicking test was performed using water at standard temperature and pressure (STP) and three arbitrarily-selected wick materials. The results, shown on Figure 2.4, are consistent with those in the literature (Dunn and Reay 1982, p. 96). 


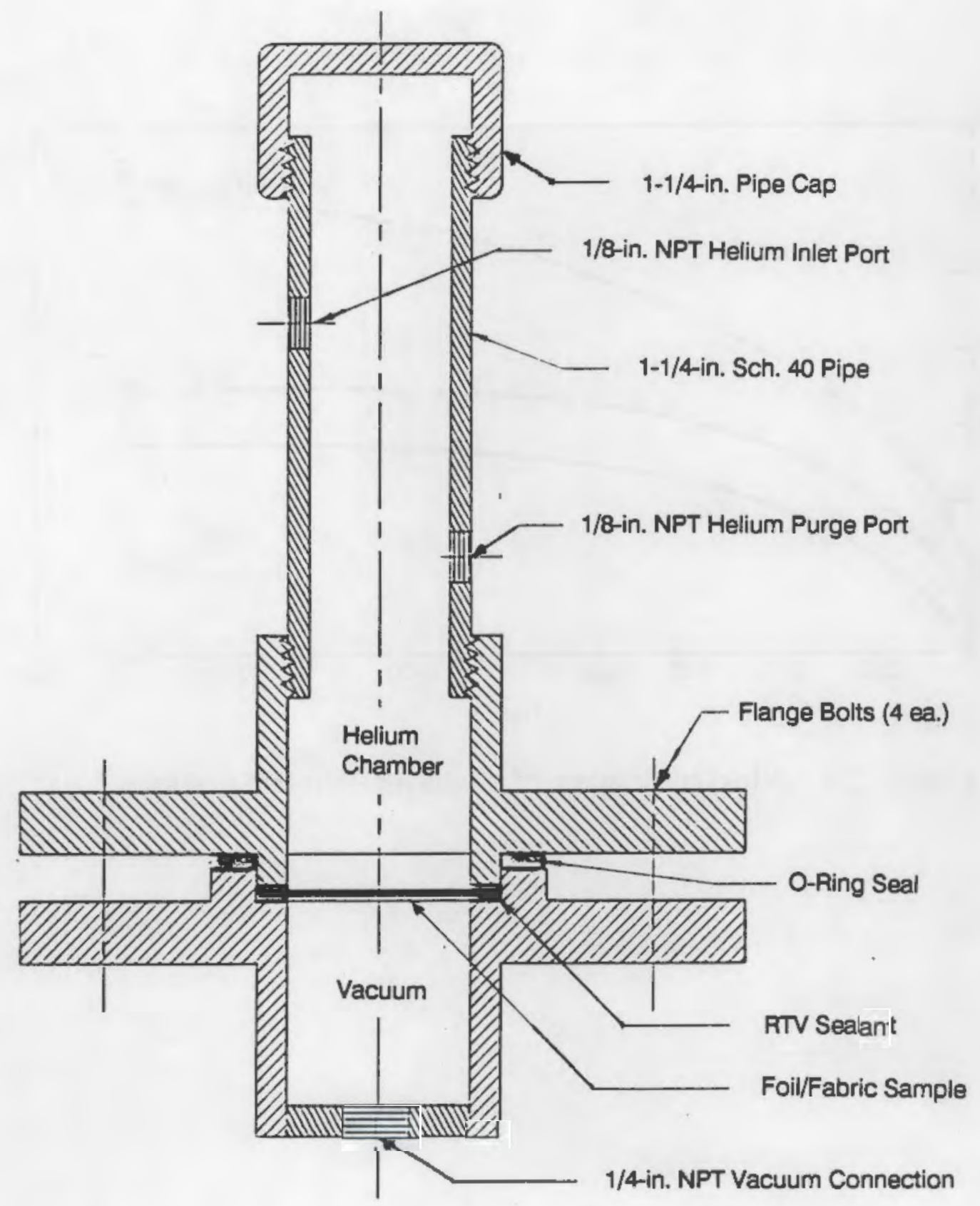

FIGURE 2.3. Sample Leak Test Fixture

These tests indicate that ceramic fiber fabrics should serve as acceptable heat pipe wicks. Ceramic wicks have been considered in the past (Dunn and Reay 1982, pp. 95, 144-146), although we have not seen heat pipe performance figures with such wicks. 


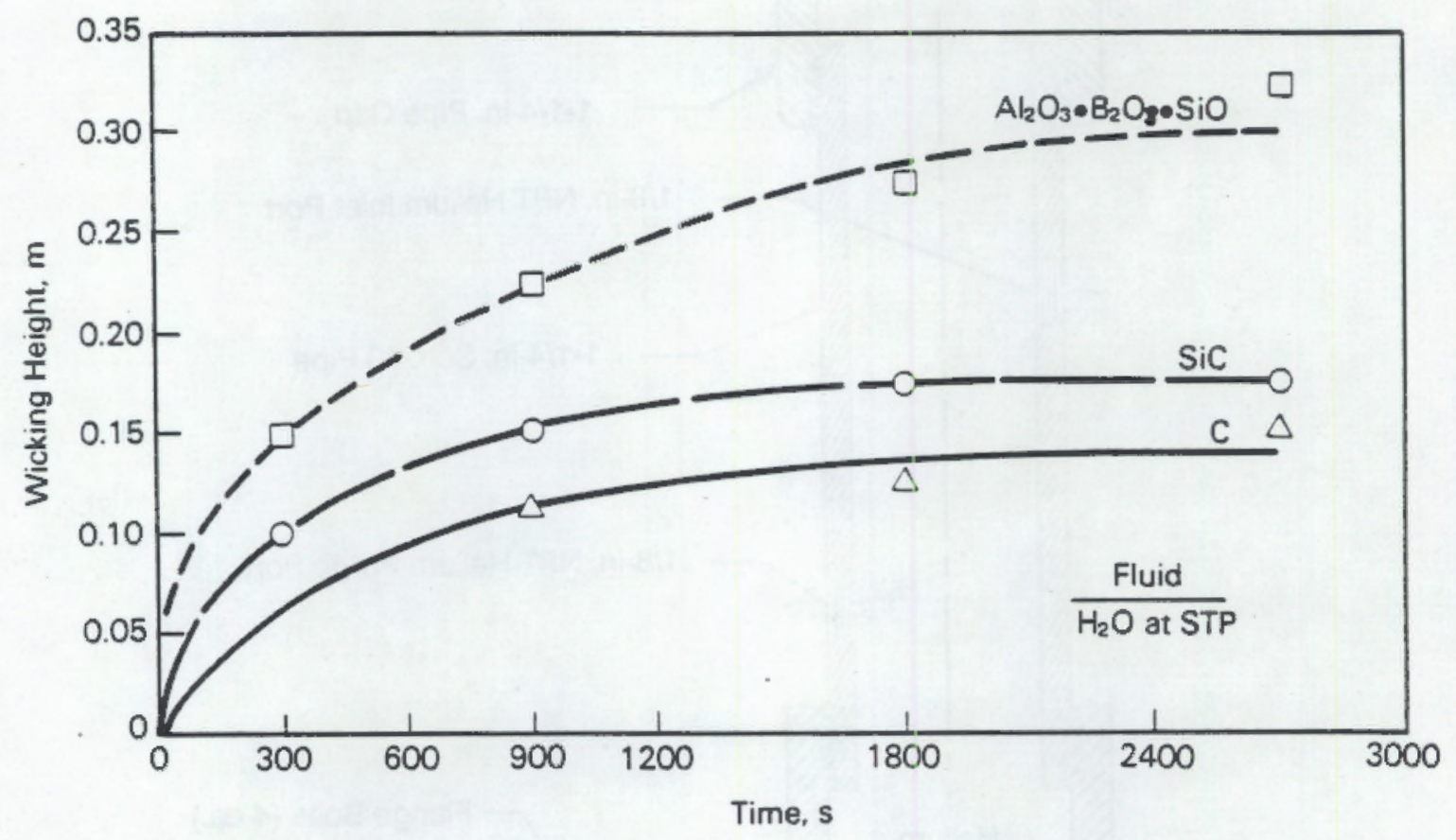

FIGURE 2.4. Wicking Heights of Standard Fabric Samples 


\subsection{SPACE RADIATOR CONCEPTUAL DESIGN AND HEAT TRANSFER ANALYSIS}

As previously mentioned, the primary purpose of this study was to design and assess radiator systems that are coupled to a closed Brayton-cycle nuclear heat engine. A helium/xenon gas mixture is assumed to be the reactor coolant fluid. The radiator designs that were the subject of this study are discussed below; any number of panel configurations could be used (Josloff, Kirpich, and Biddiscombe 1987).

Analysis is required to properly design and optimize a radiator system. Analysis is also required to permit comparison of the three studied fabric radiator designs. Computer models of the direct and secondary system radiators have been prepared for use by the ATHENA computer code; heat pipes have been examined with a code originally created at LANL and modified by PNL.

\subsection{HELIUM/XENON DIRECT PUMPED-LOOP RADIATOR}

This system is the simplest. The helium/xenon fluid is pumped directly through one or more flexible radiator panels. A panel consists of a series of parallel flow channels. Heat is transferred from the gas to the radiator wall by forced convection. The radiator walls reject heat by radiation to space. The primary feasibility issue is survivability, including leak detection and isolation.

A base model of one channel of the direct radiator was constructed for input into ATHENA (Carlson, Roth, and Ransom 1986). Modifications were then made to this model to perform sensitivity studies. The direct radiator base model (Case 1) consists of a hot entrance channel $5 \mathrm{~m}$ long and a cooler $5-\mathrm{m}$ return channel. Because one of the beneficial properties of employing a fabric radiator is its flexibility, it is difficult to guarantee a noncircular flow channel. Thus, circular flow areas were assumed. The dimensions for the geometries analyzed are indicated in figure 3.1. The analysis model neglects

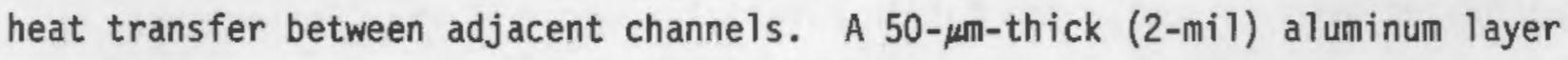
is assumed present on the interior of the $1 / 10-m m$-thick fabric wal1. One side of the radiator is assumed to be facing space; the other side faces earth. 


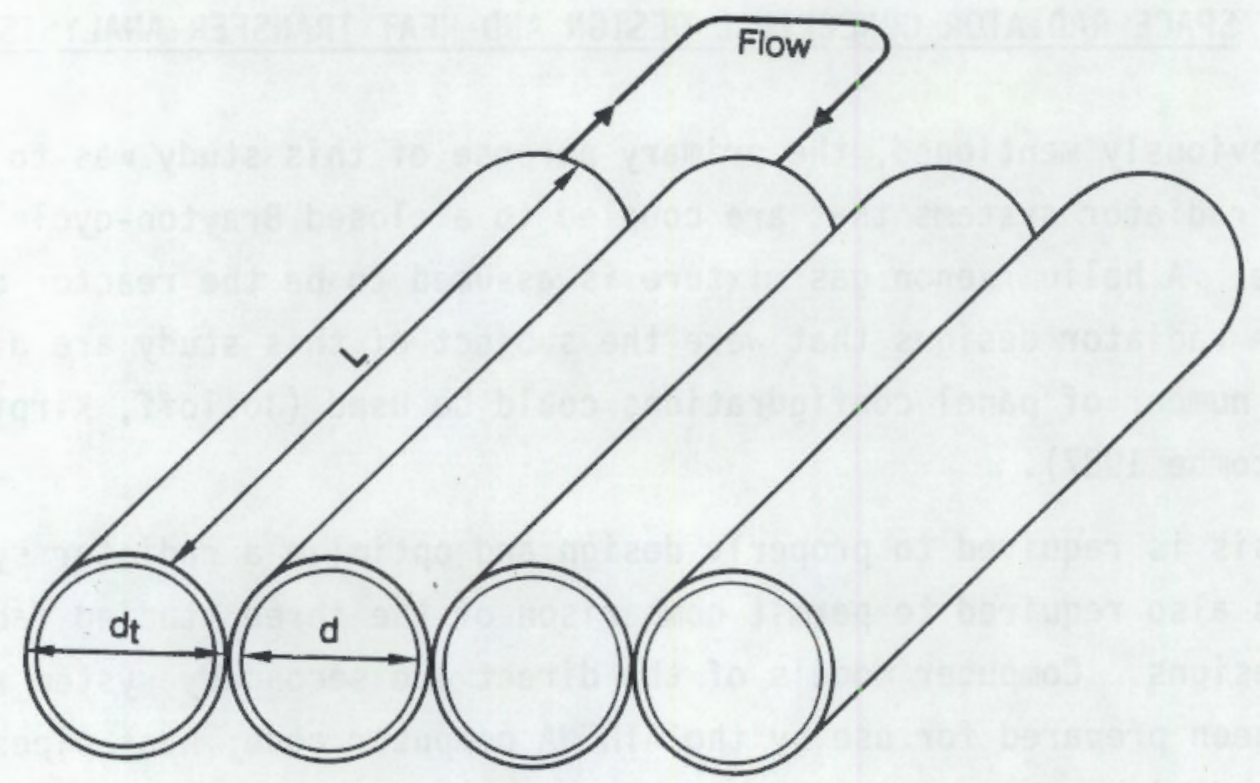

\begin{tabular}{|c|c|c|c|c|}
\hline Case & $\begin{array}{c}\text { Diameter, } \\
\mathrm{cm}\end{array}$ & $\underset{\mathrm{m}}{\text { Length, }}$ & $\begin{array}{c}\text { Flow Area, } \\
m^{2}\end{array}$ & $\begin{array}{l}\text { Channel } \\
\text { Projected Area, } \\
2 \mathrm{Ld} t, \mathrm{~m}^{2}\end{array}$ \\
\hline 1 & 3.57 & 5 & $1.0 \times 10^{-3}$ & 0.378 \\
\hline 2 & 1.0 & 5 & $7.85 \times 10^{-5}$ & 0.121 \\
\hline 3 & 2.5 & 5 & $4.91 \times 10^{-4}$ & 0.271 \\
\hline 4 & 3.57 & 10 & $1.0 \times 10^{-3}$ & 0.756 \\
\hline 5 & 1.0 & 10 & $7.85 \times 10^{-5}$ & 0.242 \\
\hline 6 & 2.5 & 10 & $4.91 \times 10^{-4}$ & 0.542 \\
\hline
\end{tabular}

\section{FIGURE 3.1. Circular Direct Radiator Design}

The radiation boundary temperature of space was assumed to be $4 \mathrm{~K}$ and for earth, $260 \mathrm{~K}$. Radiation heat transfer at the surfaces was calculated using an effective temperature-dependent, heat transfer coefficient at the aluminum liner outer surface. The heat transfer coefficients for the sides facing space and earth are different. Both heat transfer coefficient values were calculated accounting for the fabric material transmissivity, reflectance, and absorption. Heat conduction through the fabric was assumed small and negligible. The thermal resistance diagram used to determine the radiativeheat-transfer coefficients is shown in Figure 3.2. The relationships 


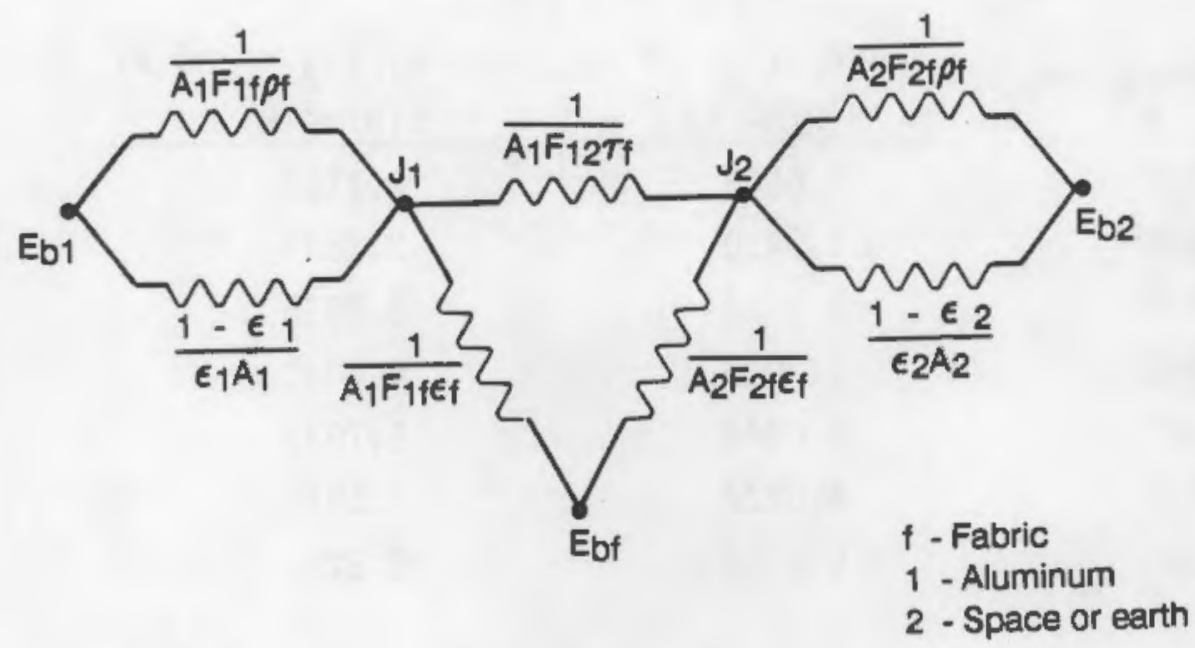

FIGURE 3.2. Thermal Resistance Model for Radiator Surface

indicated in this figure were simplified by assuming that space or earth are black bodies $\left(\epsilon_{2}=1.0\right)$, that all viewfactors are equal to $1\left(F_{12}=F_{1 f}=F_{2 f}\right.$ $=1.0$ ), and $A_{2}$ is much larger than $A_{1}$. Assuming that treated aluminum has an emissivity of 0.6 and that the fabric is made of $\mathrm{SiO}_{2}$ with an areal density of $120 \mathrm{~g} / \mathrm{m}^{2}(\rho=0.46, \tau=0.5, a=\epsilon=0.04)$, the radiative-heat-transfer coefficients indicated on Table 3.1 are calculated using

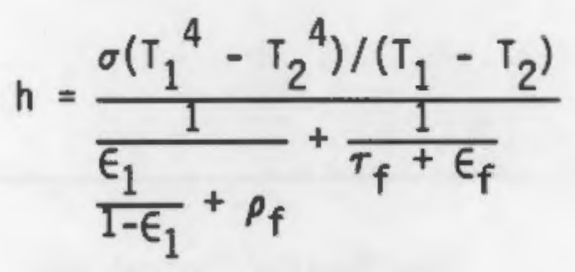

Using the cycle values supplied for the $30-\mathrm{kW}$ closed Brayton cycle, the mass fraction of the helium was calculated to be 0.072 and the xenon mass fraction was calculated to be 0.928 . These values translate to a helium volume fraction of 0.716 and a xenon fraction of 0.284 . Assuming all helium/xenon flow in the channels, the results of the ATHENA parametric study are indicated on Figures $3.3,3.4$, and 3.5. These figures reveal that larger flow 
TABLE 3.1. Calculated Radiative Heat Transfer Coefficients with Aluminum Surface Treatment

\begin{tabular}{|c|c|c|}
\hline $\begin{array}{c}\text { Temperature, } \\
\mathrm{K}\end{array}$ & $\begin{array}{c}\text { Space, }\left(T_{2}=4 \mathrm{~K}\right) \\
\mathrm{h}\left(\mathrm{W} / \mathrm{m}^{2} \mathrm{~K}\right) \\
\end{array}$ & $\begin{array}{c}\text { Earth, }\left(T_{2}=260 \mathrm{~K}\right) \\
\mathrm{h}\left(\mathrm{W} / \mathrm{m}^{2} \mathrm{~K}\right)\end{array}$ \\
\hline 300 & 0.6568 & 2.1184 \\
\hline 350 & 1.0410 & 2.7834 \\
\hline 400 & 1.5517 & 3.6056 \\
\hline 450 & 2.2069 & 4.6031 \\
\hline 500 & 3.0246 & 5.7937 \\
\hline 550 & 4.0227 & 7.1956 \\
\hline 600 & 5.2194 & 8.8267 \\
\hline
\end{tabular}

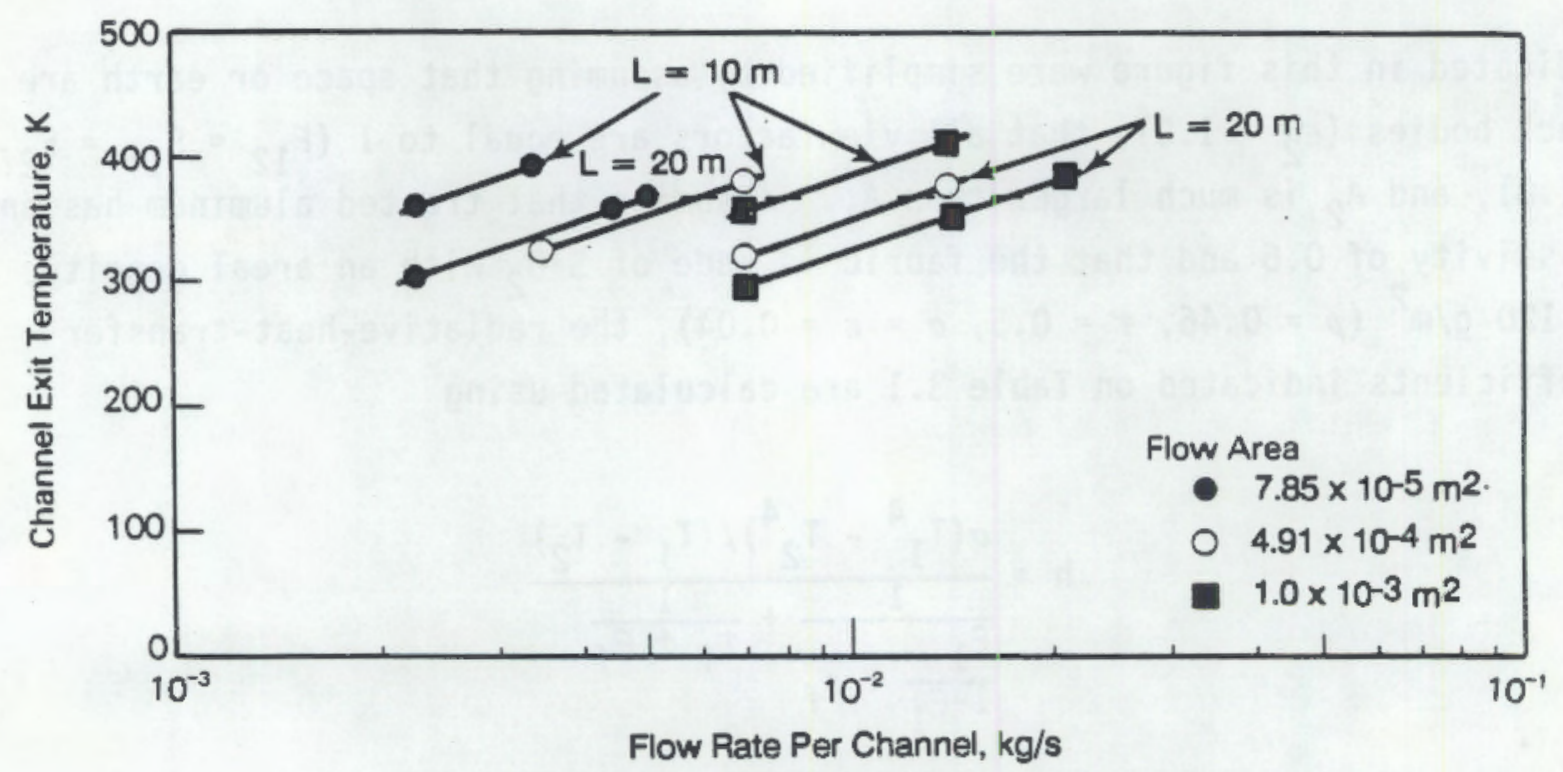

FIGURE 3.3. Channel Exit Temperature For Helium/Xenon Flow

areas remove more heat for an equivalent length. However, the temperature drop along the channel is larger for the smaller areas. The design conditions of the assumed Brayton cycle require a radiator outlet temperature of $366.5 \mathrm{~K}$. The required mass flow to meet this criterion for a given flow area 


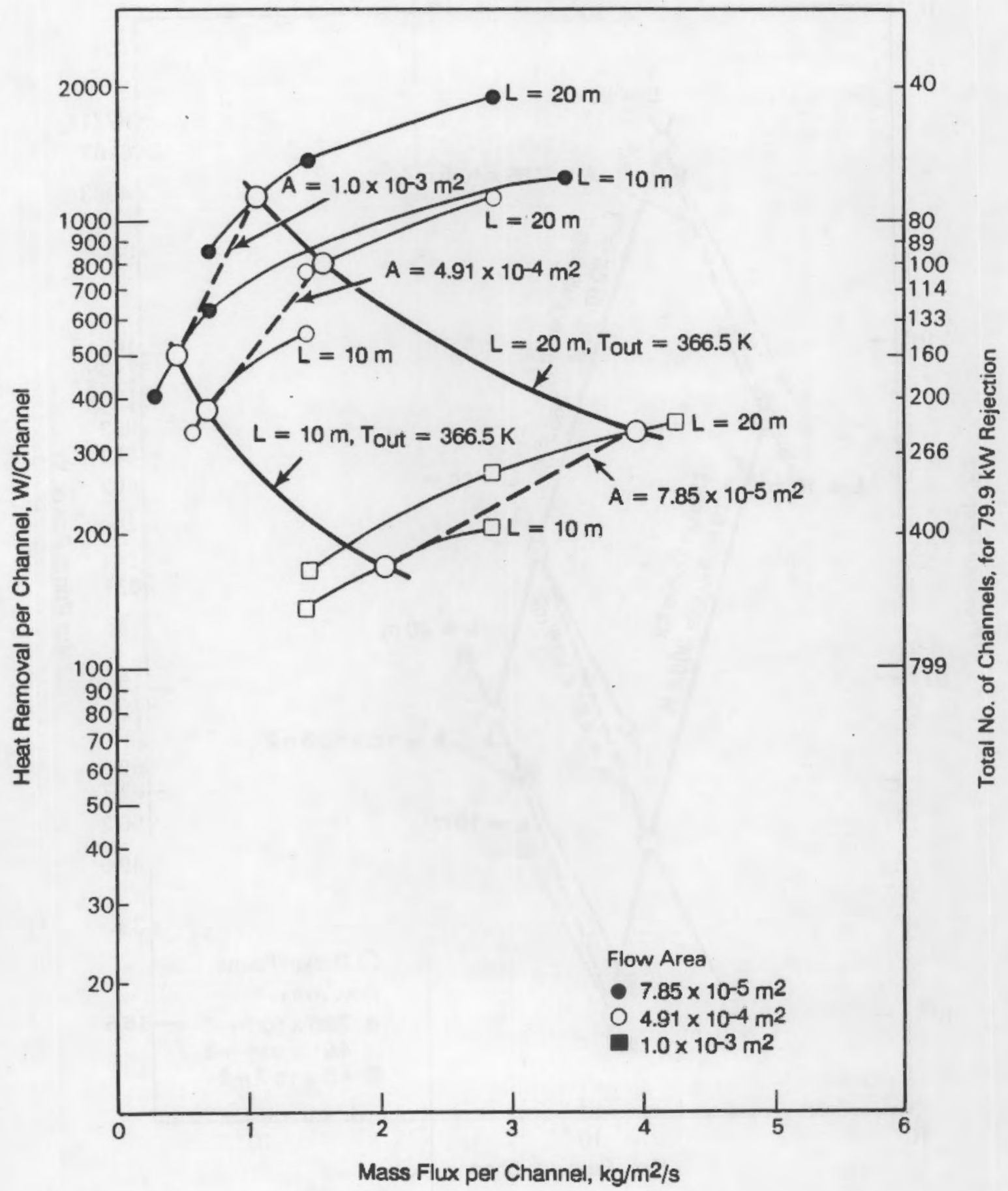

FIGURE 3.4. Radiator Heat Removal Design Curve For Helium/Xenon Flow 


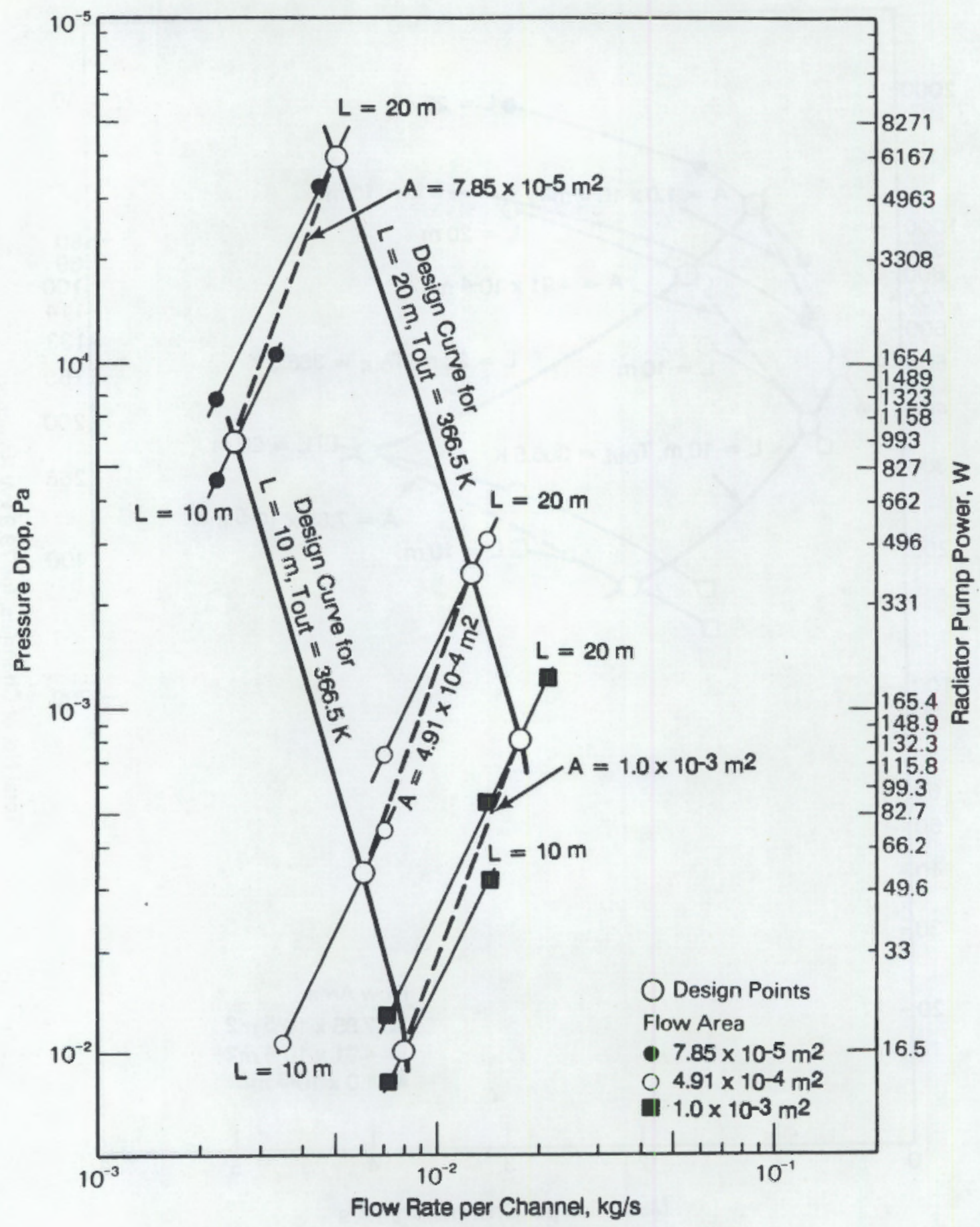

FIGURE 3.5. Radiator Pressure Drop Design Curve For Helium/Xenon Flow 
and total length are indicated on Figure 3.3. Using this information, the design curves of Figure 3.4 and 3.5 were developed. Figure 3.4 could be used to obtain the required size of the radiator. For instance, if 93 channels are desired for a 79.9-kW, 10-m-long (5-m inlet and 5-m return) radiator, with a $1 \times 10^{-3}-\mathrm{m}^{2}$ flow area, the required channel mass flux is about 8.5 $\mathrm{kg} / \mathrm{m}^{2} / \mathrm{s}$ with $860 \mathrm{~W}$ heat removal per channel. An equivalent $20-\mathrm{m}-1$ long radiator would require a mass flux of $18 \mathrm{~kg} / \mathrm{m}^{2} / \mathrm{s}$ and supply a heat removal of $1900 \mathrm{~W}$ per channel. The total number of channels required would be 43 . Both of these designs would supply a radiator outlet temperature of $366.5 \mathrm{~K}$. The resultant channel pressure drop can be obtained from Figure 3.5. The pressure drop would be about $105 \mathrm{~Pa}$ for the 10-m-long design, and $820 \mathrm{~Pa}$ for the $20-\mathrm{m}$ design.

Using Figures 3.4 and 3.5 , the conditions specified by the designed Brayton cycle can be used to determine the design points of a number of radiators that can meet the desired operating requirements. For the six sample design points, Table 3.2 lists the required projected radiator surface area for one side. The total projected surface area is twice this value. The required projected areas vary between 32 and $35 \mathrm{~m}^{2}$. Because the radiator inlet and outlet temperatures are fixed, the temperature gradient along a channel is approximately the same for all the radiator design points. Because the gradients are about equal, the radiator surface area required for rejecting 79.9 kWt at the Brayton-cycle design operating conditions are about equal for all the radiator design points. This occurs because heat transfer from the radiator is dominated by radiation heat transfer from the outer surface. Therefore, it can be concluded that the required radiator surface area is $35 \mathrm{~m}^{2}$ or slightly less for all radiator design points irrespective of channel flow area or channel mass flow.

The weight of the radiator system for all six sample design points ranges between 28 and $36 \mathrm{~kg}$. Therefore, a slight weight savings exists by using smaller-diameter channels. However, when the projected area is divided by the weight, the resulting values indicated on Table $3.2 \mathrm{fall}$ between 0.85 and 1.02. It should be noted the calculated radiator weight does not include weights for the radiator inlet or outlet headers, any failure isolation equipment, or redundant channels. 
TABLE 3.2. Design Conditions for Helium/Xenon Cases Studied

\begin{tabular}{|c|c|c|c|c|c|c|c|c|c|}
\hline $\begin{array}{c}\text { Flow Area, } \\
-2 \\
\end{array}$ & $\begin{array}{l}\text { Channel } \\
\text { Length } \\
\text { (a) } \\
\end{array}$ & $\begin{array}{l}\text { Heat Renoval } \\
\text { per Channel, }\end{array}$ & $\begin{array}{l}\text { No. Channels } \\
\text { (for } 70.8 \mathrm{kll} \\
\text { renoval) } \\
\end{array}$ & $\begin{array}{l}\text { Projected } \\
\text { Area, } n^{2(b)}\end{array}$ & $\begin{array}{c}\text { Voight, (c) } \\
\text { kg } \\
\end{array}$ & $\begin{array}{l}\frac{\text { Ioight }}{\text { Projected Area, }} \\
\mathrm{kg} / \mathrm{c}^{2} \\
\end{array}$ & $\begin{array}{c}\text { Total } \\
\text { Flow Rate, } \\
\mathrm{kg} / \mathrm{s} \\
\end{array}$ & $\begin{array}{l}\text { Pressure } \\
\text { Drop, } \mathrm{Pa} \\
\end{array}$ & $\begin{array}{l}\text { Requi red } \\
\text { Pumping } \\
\text { Power, (d) } \\
\end{array}$ \\
\hline $1 \times 10^{-3}$ & 10 & $860(872)^{(0)}$ & 93 (92) & $35.2(34.8)$ & $35.9(35.5)$ & 1.62 (1.02) & $0.753(0.745)$ & 165 (163) & $17.4(17.0)$ \\
\hline $1 \times 10^{-3}$ & 20 & 1980 & 43 & 32.5 & 33.2 & 1.02 & 6.753 & 826 & 135.6 \\
\hline $4.01 \times 10^{-4}$ & 10 & 648 & 125 & 33.8 & 32.9 & $\oplus .97$ & 0.758 & 380 & 62.9 \\
\hline $4.81 \times 10^{-4}$ & 20 & $1370(1362)$ & $59(59)$ & $32.0(32.0)$ & $31.1(31.1)$ & $0.97(0.97)$ & $0.743(0.743)$ & $2456(2513)$ & $405.3(415.7)$ \\
\hline $7.85 \times 10^{-5}$ & 10 & 275 & 291 & 35.2 . & 29.9 & 0.85 & 6.736 & 5850 & 967.7 \\
\hline $7.85 \times 10^{-5}$ & 20 & $6 \varnothing 0$ & 134 & 32.4 & 27.6 & 6.85 & 0.673 & 46866 & 6617.0 \\
\hline
\end{tabular}

\footnotetext{
(a) Total length fron radiator inlet to outlet

(b) For one side. Total projected area is twice this value.

(c) Includes liner, fabric, braze, and gas only. Does not include inlet or outlet headers, isolation oquipment, or rodundant channels.

(d) Assuning punp officiency of 1.0

(e) Nubbers in parentheses represent values obtained fron an actual ATHEMA run.
} 
The proposed direct radiator design provides a promising method for rejecting heat. The design of a direct radiator for a nuclear helium/xenon cooled Brayton cycle using a metal-lined fabric material can result in lightweight radiator designs with area to weight ratios below $1.0 \mathrm{~kg} / \mathrm{m}^{2}$. The actual design will be dictated by pumping power, survivability (such as channel redundancy and isolation designs), and fabricability concerns. Therefore, the exact choice of a design is not possible at this early stage. However, the results, curves, and methods presented in this section can be used for scoping studies for future design efforts, which would serve as a basis for more exact design calculations.

\subsection{LITHIUM SECONDARY-SYSTEM PUMPED-LOOP RADIATOR}

This design removes heat from the helium/xenon primary system through an intermediate heat exchanger. The heat is transferred to a secondary system consisting of a one-phase, liquid-metal working fluid such as lithium or sodium/ potassium. Heat is removed from the secondary system through a liquid-metal radiator consisting of one or more flexible radiator panels. These panels would consist of circular channels connected by beryllium spacers that are bonded to the channel liner and act as fins. This radiator system has better heat transfer and survivability characteristics than the direct radiator, but raises other concerns such as compact heat exchanger design, material compatibility, and liquid-metal thaw problems. A detailed analysis of this design was not performed here but is recommended as a future activity.

\subsection{HEAT PIPE RADIATOR}

An alternative to the pumped loops described above is a variation on the familiar heat pipe technology. Rather than constructing a heat pipe in the traditional manner, with a rigid outer wall, we conceive an advanced heat pipe fabricated in a triple-layered, fully-flexible configuration (see Figure 1.4). The benefits of such an approach are manifold: construction and reproducibility problems are eased; low mass is readily attained; and, as a final boon, flexibility is retained not only during launch/startup, but potentially during the entire lifetime of the radiator system. 
Heat pipe analysis is more complex than that of pumped loops because of the larger number of variables, many of which, lacking specific test data, can only be estimated. The following analysis is by no means optimized, as only a few options have been examined and these not fully. We believe that optimized fabric heat pipes could be constructed significantly lighter than the current analysis shows.

The LANL code employed is not a systems code. It treats the heat pipe as a one-dimensional, compressible-flow, thermodynamic system, consisting solely of the working fluid (Prenger 1979). The base code has been modified somewhat by incorporating many other fluid property tables (Brennan and Kroliczek 1979) and by calculating the mass of the fluid and heat pipe components. A number of code runs have been made; sample output is provided in Appendix A. Note that the mass estimate shown (Table 3.3) does include an assumed $0.05-\mathrm{kg} / \mathrm{m}^{2}$ fabric of braze/bonding material for the metallic liner. (The mass estimates for the pumped-loop designs also included such mass). Because optimal bonding techniques have yet to be developed, it would be premature to include the braze mass used in the current test samples (which ranged up to $0.6 \mathrm{~kg} / \mathrm{m}^{2}$ of fabric). One additional comnent: the heat pipe mass/area requirement calculation does not include the mass of the arteries. The reasons are discussed below.

Analys is was begun by examining the simplest wick structure, an annular homogeneous one consisting of one or more layers of ceramic wick bonded to an impermeable metallic foil. In a 5-m condenser length, this design consistently was a poor performer, with an unacceptably low capillary pumping limit. This forced us to examine the currently preferred space heat pipe wick concept, which employs arteries for efficient liquid return to the evaporator (Dunn and Reay 1982, p. 95). Although flexible heat pipe designs employing arteries have been studied and constructed (Ernst 1981; Brennan and Kroliczek 1979, Vol. 1, p. 341), they can be problematic and are usually to be avoided (Josloff, Kirpich, and Biddiscombe 1987).

The design we have selected is assumed to contain artery-type flow passages woven into the wick structure; no separate arteries exist. These artery-type 
TABLE 3.3. Heat Pipe Performance Summary

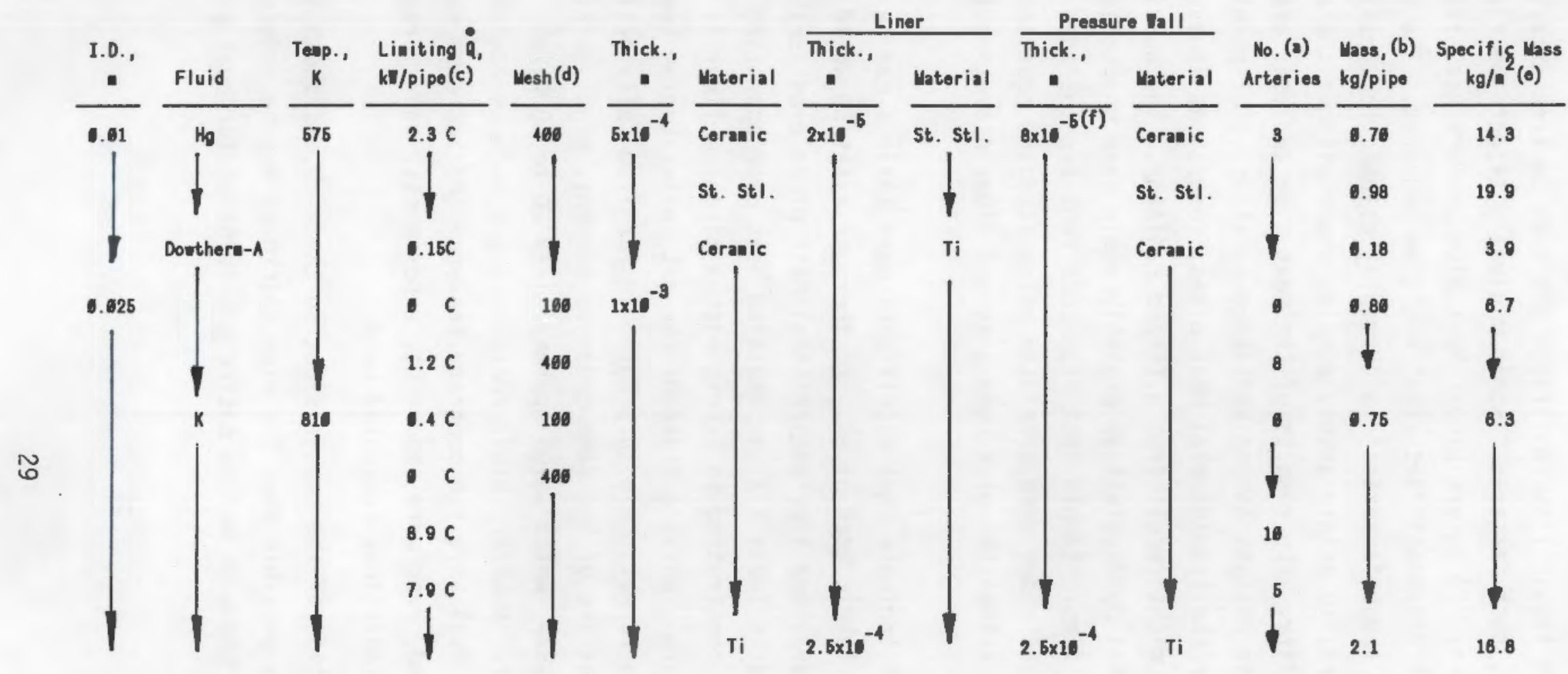

(a) Assumed to be part of wick strueture and not included separately in mass calculation

(b) For all heat pipes, lengths were: evaporator section, $.4 \mathrm{a}$; adiabatic, $.1 \mathrm{~m}$; condenser, $5.6 \mathrm{n}$.

(c) $C=$ capillary; $E$ = entrainmont; $S=$ sonic (linits)

(d) Por inch.

(e) Assumes heat rejection fron both sides of radiator panels consisting solely of contiguous heat pipes and mass based on projected area.

(f) Based on a yarn strength of $1550 \mathrm{MPa}\left(2.25 \times 10^{5}\right.$ psi) (Fareed et al. 1987) and assuning little degradation in strength to about $790 \mathrm{~K}$ (Sawko and Tran 1985) If the loss in strength incurred by the twisting of fibers into yarn could be reduced, even greater strength aight be feasible. Also, 0.7 upa (190 psia) pressure and a safety factor of 2 were assuned. 
passages should be achievable in a variety of ways and should serve the same function of lessened return liquid flow resistance achieved by true arteries. Given their small diameter, such "arteries" would minimally affect the flexibility of the wick structure. To ensure proper heat pipe performance after prolonged stowage, multiple redundant "arteries" would be required. The proposed design incorporating these "arteries" is currently assumed to consist of a variable-mesh structure, to attain artery pumping power without the associated complexity and fragility. The results of the heat pipe analyses are shown in Table 3.3. All the designs assume radiators constructed of parallel, contiguous heat pipes. For the liquid-metal heat pipes, reductions in mass and improved survivability might result from a finned radiator. The working fluids possessing low thermal conductivities probably would have unacceptable temperature gradients with fins. Sample heat pipe code runs are included in Appendix A. The input values shown were generated using standard equations (Chi 1976, pp. 35-42), and assume the wick pore size and fiber diameters to be equal.

The calculated results indicate that significant mass savings can be realized with the proposed fabric heat pipes. Further optimization would likely improve this mass advantage over conventional heat pipes even further. For example, as illustrated in Table 3.3, a potassium heat pipe operating at $810 \mathrm{~K}$ (SP-100 environment) constructed in fabric with a titanium liner is. estimated to weigh $10.3 \mathrm{~kg} / \mathrm{m}^{2}$, while a state-of-the-art, all-titanium heat pipe weighs $26.8 \mathrm{~kg} / \mathrm{m}^{2}$. To repeat, this $10.3 \mathrm{~kg} / \mathrm{m}^{2}$ is far from fully optimized, although material dimensions are of the same order as current, highly-optimized designs (McNamara et al. 1987), which weigh approximately 20 to $40 \mathrm{~kg} / \mathrm{m}^{2}$ (Dearien and Whitbeck 1987). However, other considerations such as launch or survivability criteria may well have the contrary tendency and increase mass. Only additional analyses and, even more important, experiments, can improve the accuracy of the mass predictions presented here.

Note that a major portion of the mass resides in the wick, as shown in Appendix A. It is entirely possible that the wick thickness may be reduced considerably, or even that the wick may be entirely eliminated for heat pipes 
smaller and shorter than the 5-m lengths analyzed here. The corrugated surface of the thin metal liner, naturally formed from internal pressure forces pressing it against the weave of the fabric outer wall, may provide sufficient wicking to feed several return arteries without the need for a conventional wick. This approach has been studied in some detail by LANL (Meier, Girrens, and Dickinson 1980). 



\subsection{MICROMETEOROID ANALYSIS}

To properly assess the operational lifetime survivability of the heat rejection system, a realistic design will need to address system threats posed by space and man. System threats posed by man include not only passive orbiting space debris, but also active threats, such as directed and kinetic energy weapons.

An assessment of the threat of impact from space orbital debris will not be attempted here because of its complexity and the variability of the threat due to orbital direction, altitude, and the orientation of the heat rejection system to the debris path. However, preliminary calculations by PNL and experiments by the National Aeronautics and Space Administration (NASA) indicate that the threat posed by orbital debris is comparable to that posed by micrometeoroids.

\subsection{APPROACH}

Meteoroids can be characterized as small solid particles ranging in size from $10^{-12}$ to $1 \mathrm{gm}$ in mass, traveling through interplanetary space with an average velocity of $20 \mathrm{~km} / \mathrm{s}$ and a density of $0.5 \mathrm{~g} / \mathrm{cm}^{3}$. While the masses of micrometeoroids are generally small, the impact of these high-velocity particles on unprotected spacecraft and equipment can result in siginificant damage. As a consequence, extensive investigations have been and are being made to further characterize their masses, velocities, and quantities, so future spacecraft and equipment designs can be improved for added protection against them. As a result of these studies, the meteoroid mass flux has been characterized as comprising two components--an average sporadic background flux and a stream flux associated with annual meteor showers.

The Near Earth to Lunar Surface Meteoroid Environmental model was developed by NASA to approximate the average sporadic mass flux for use in spacecraft design. To obtain a total meteoroid threat assessment for both the average sporadic and stream meteoroid components, this model has been modified to account for the stream meteoroid component. Figure 4.1 provides an estimate 


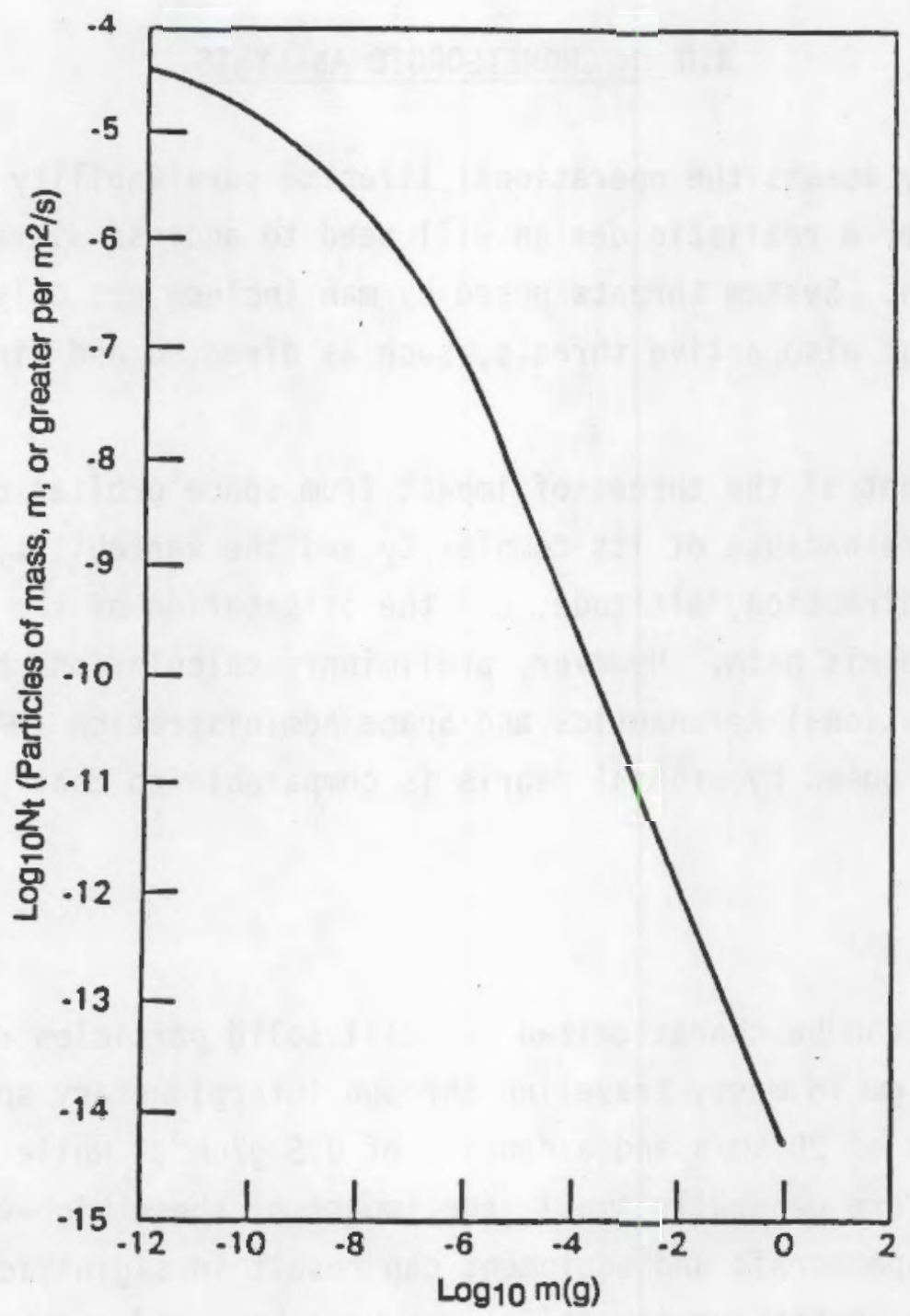

FIGURE 4.1. Average Cumulative Meteoroid Mass Flux for Near-Earth Orbits of the average cumulative micrometeoroid mass flux as a function of micrometeoroid mass (Cour-Palais 1969). The corrected total meteoroid mass flux for meteoroid masses of interest, $10^{-6}$ to $1 \mathrm{gm}$, is given by

$$
\log _{10} N_{t}=-14.37-1.213 \log _{10} m
$$

where $N_{t}$ is the number of meteoroids of mass $m$ or greater, $m^{2}-s$, and $m$ is the meteoroid mass, $g$. 
The total meteoroid mass flux is then corrected for differences between near earth and deep space operations, primarily the shielding effects by the earth, $E$, and deviations in the mass flux due to gravitational influence, $G_{e}$. These, in turn, are calculated as follows:

$$
E=0.5\{1+\cos [\arcsin 6378 /(6378+H)]\}
$$

where $\mathrm{H}$ is the orbital altitude of the spacecraft, $\mathrm{km}$, and

$$
G_{e}=0.568\{1+0.761[6378 /(6378+H)]\}
$$

Figure 4.2 shows the product of $G_{e} E$ as a function of spacecraft orbital altitude.

In assessing the probability of survival for various system configurations, the thickness of component walls necessary to prevent incipient penetration by an impacting particle of specified mass and velocity is given by

$$
t=k_{1} m_{p}^{0.352} \rho_{p}^{0.167} v^{0.875}
$$

where $\quad t=$ monolithic barrier thickness, $\mathrm{cm}$

$$
\begin{aligned}
m_{p}= & \text { particle mass, } g \\
\rho_{p}= & \text { particle density, } \mathrm{g} / \mathrm{cm}^{3} \\
v= & \text { particle velocity, } \mathrm{km} / \mathrm{s} \\
k_{1}= & \text { constant determined experimentally for materials of specific } \\
& \text { interest and listed in Table } 4.1 .
\end{aligned}
$$




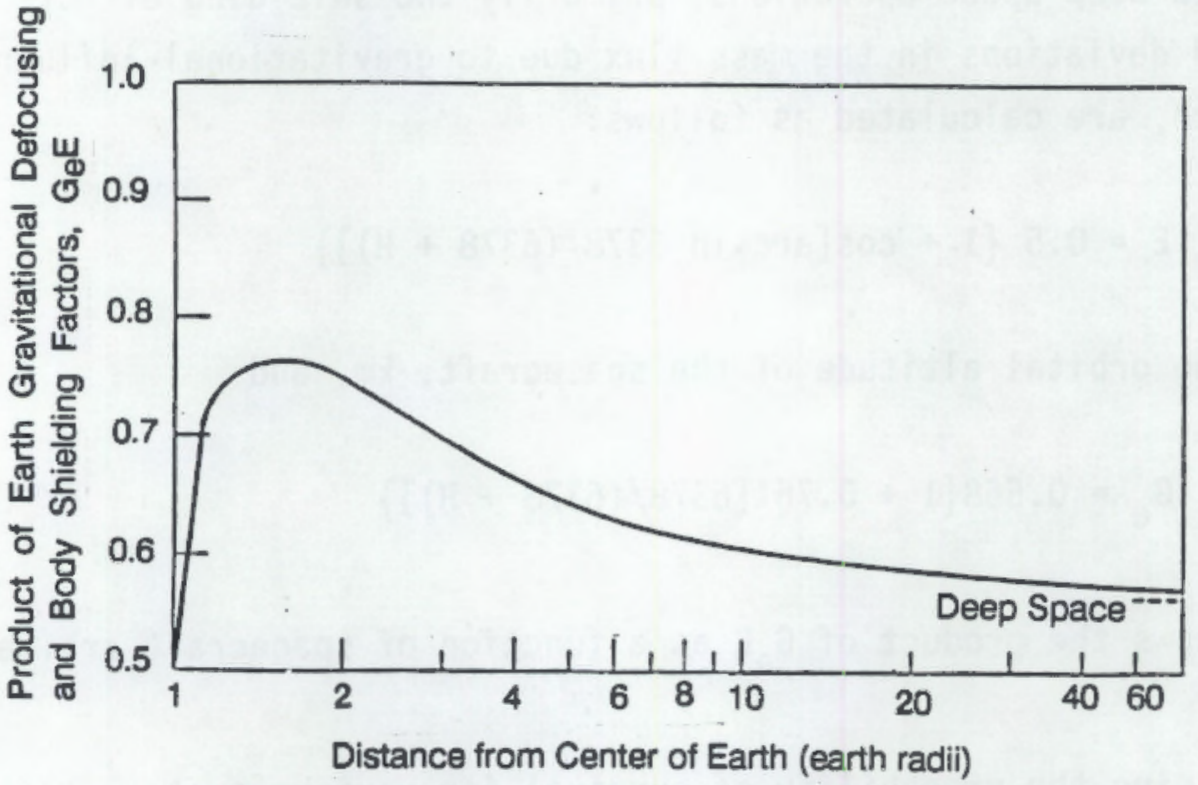

FIGURE 4.2. Product of Earth's Gravitational Defocusing and Body Shielding Factors, $G_{e} E$, as a Function of Distance from Earth's Center

Because the metallic-ceramic fabric materials in this study are not homogeneous structures, and because of their intrinsically higher yield strengths, it has been suggested(a) that the incipient penetration equation be referenced to aluminum alloys and modified as follows:

$$
t=k_{1} m_{p}^{0.352} \rho_{p}^{0.1667} v^{0.875}\left(\frac{483}{\sigma_{y s}}\right)^{\frac{1}{2}}
$$

where $k_{1}$ is specified as 0.57 and $\sigma_{y s}$ is the yield strength for the ceramic fabric fibers (MPa) at operating temperature, assumed to be 3,000 $\mathrm{MPa}$ for $\mathrm{SiO}_{2}$ at $452 \mathrm{~K}$. While it is recognized that fabric materials in general do not demonstrate yield strengths as high as the individual fibers, it is assumed that, because the hypervelocity impact is essentially instantaneous, the

(a) Cour-Palais, B. September 1987. Personal communication, NASA Johnson Space Center, Houston, Texas. 
TABLE 4.1. Constants for Threshold Penetration for a Monolithic Barrier at 298 K (Fraas 1986; Lundberg et al. 1982)

\begin{tabular}{lcc}
\multicolumn{1}{c}{ Material } & $k_{1}$ \\
\cline { 3 - 3 } Aluminum alloys & 0.54 to 0.57 \\
Stainless steel & 0.32 to 0.38 \\
Magnesium-1ithium & 0.80 \\
Niobium alloys & 0.34 \\
Titanium and titanium alloys & 0.57
\end{tabular}

material does not have time to react; the result is ultimate yield strengths that approach the strengths of the fibers themselves. This relationship for incipient barrier thickness can then be transposed to solve the particle mass capable of penetrating a specified wall thickness at a given velocity:

$$
m_{1}=t^{2.84} k_{1}-2.84 \rho_{p}^{-0.474} v^{-2.485}\left(\frac{483}{\sigma_{y s}}\right)^{-1.422}
$$

Equation (4) can be substituted into Equation (1) and transposed to obtain a direct relation for the micrometeroid mass flux capable of incipient penetration of a monolithic barrier of a specific thickness.

$$
\mathrm{N}_{t t}=\frac{4.266 \times 10^{-15} \mathrm{t}^{-3.445} \mathrm{k}_{1}^{3.445} \rho_{\mathrm{p}}^{0.575} \mathrm{v}^{3.014}\left(\frac{483}{\sigma_{\mathrm{ys}}}\right)^{1.725}}{\mathrm{G}_{\mathrm{e}} \mathrm{E}}
$$

Values of $\mathrm{N}_{\mathrm{tt}}$ are then calculated over the range of velocity intervals and a net flux increment developed. The net flux increment is then multiplied by its associated probability and the results summed to develop a total lethal micrometeoroid mass flux, $\mathrm{N}_{\mathrm{lt}}$. Figure 4.3 provides an estimate of the probability distribution for velocities of observed meteoroids (Cour-Palais 


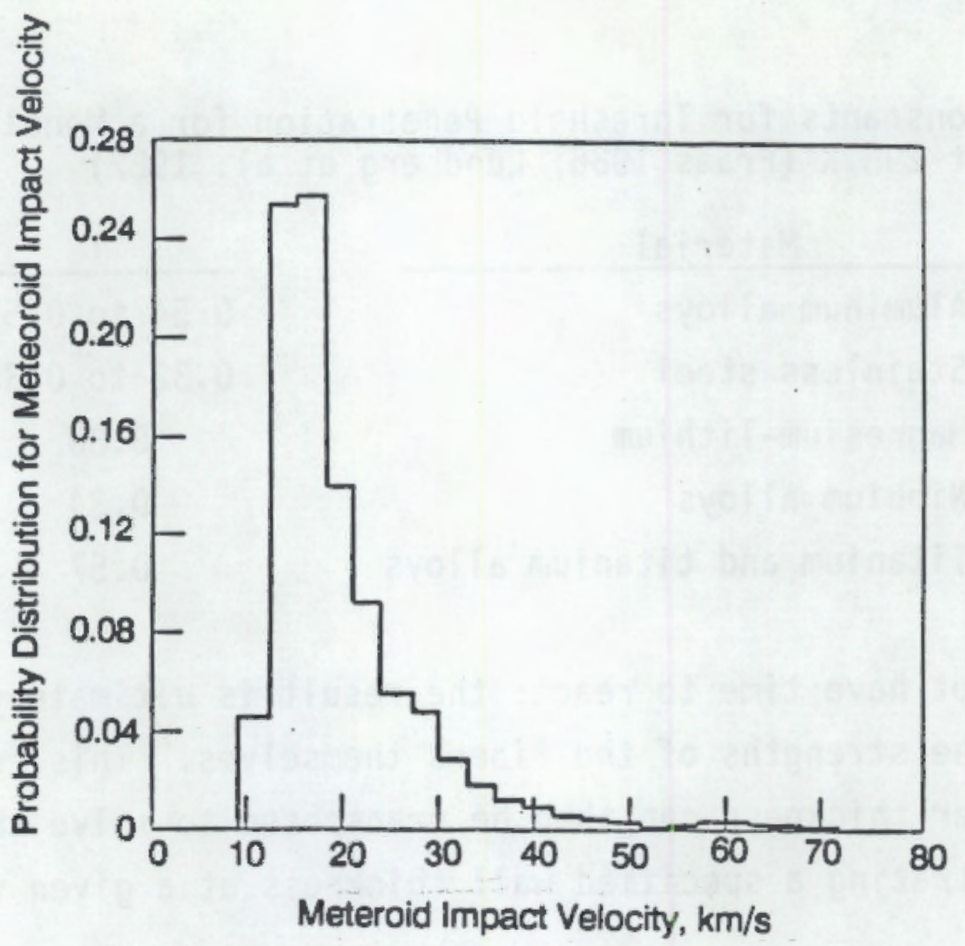

FIGURE 4.3. Probability Distribution of Observed Meteoroid Velocities

1969). In doing so, the mean probability velocity for an impacting particle can be shown to be $25.21 \mathrm{~km} / \mathrm{s}$ (Fraas 1986).

With the micrometeoroid mass flux so defined, the probability of impact on a specified heat rejection system with known areas and operational lifetime by $n$ or less particles is determined by the Poisson formula,

$$
P_{(h \leq n)}=\exp \left(-N_{\ell t} A t\right) \sum_{n=0}^{r=n} \frac{\left(N_{l t^{A t}}\right)^{r}}{r !}
$$

where $P_{(h \leq n)}=$ probability of impact by $n$ or fewer lethal particles

$$
\begin{aligned}
N_{l t}= & \text { total lethal particle flux, particles } / m^{2}-s \\
A= & \text { total exposed surface area, } m^{2}(2 x \text { projected area for flat } \\
& \text { panels) } \\
t= & \text { operational lifetime, } s \\
r= & \text { specified number of impacts. }
\end{aligned}
$$


Because the heat rejection systems to be studied will include redundancy, Equation (6) can be used to assess the probability that less than a specific number of penetrations will occur for a specific design. Conversely, it then holds that if various system characteristics are known (i.e., material composition, surface area, number of heat rejection loops, number of allowable penetrations) and system reliability is specified, a required wall thickness can be calculated that will prevent incipient penetration by impacting particles. This, in turn, can be used to calculate corresponding heat rejection system masses.

\subsection{PUMPED-LOOP SURVIVABILITY CALCULATIONS}

Based on the equations and methodology described, a computer program was written to perform survivability calculations for a space-based heat rejection system. The program assumes that the fabric materials proposed behave as monolith barriers ratioed to a reference yield strength of $483 \mathrm{MPa}$ (70 k psia) (equivalent to Al-6061T at room temperature). In addition, the code assumes that the radiator surfaces are comprised of tubes only, without the benefit of radiating fins, arranged in a flat panel configuration. Based on these assumptions, the total projected surface area of the heat rejection system is calculated for use in the survivability calculations.

The following items must be specified:

- the minimum required number of loops that the system must contain at end of life

- number of additional loops to consider

- the diameter and length of the exposed loops

- density of the fabric and metallic liner materials

- strength of the fabric materials

- operational characteristics of the heat rejection system (i.e., reliability, operational lifetime, and orbital factors). 
The micrometeoroid lethal mass flux is then found by using a Newton-Raphson convergence method, and the associated system armor mass is calculated. The number of total system loops is incremented by 1 , and the process is repeated. A listing of the survivability assessment program and calculation runs are found in Appendix B.

Using this program, a series of parametric cases was run to determine the probability of system survivability and the effect of system redundancy on total radiator mass for the pumped-loop systems described in Table 3.2. In these calculations, it is assumed that each radiator system has an operational lifetime of $10 \mathrm{yr}$ and is in near-earth orbit such that the orbital correction factor is 0.7 . The fabric composite material is composed of a $0.002-\mathrm{cm}-$ thick titanium alloy inner liner, for which no credit is taken in the survivability calculations. The outer structural material is assumed to be a silicon dioxide fabric material with a density of $1.2 \mathrm{~g} / \mathrm{cm}^{3}$ (assuming a $50 \%$ porosity) and an ultimate fiber yield strength of $3,000 \mathrm{MPa}$ at $452 \mathrm{~K}$. In addition, it is assumed that each pumped loop can be isolated as it fails. The reader should note that the intent of these calculations is to assist in defining the cost of system survivability. System masses reported here are for fabric/ foil materials alone and do not include working fluids, valves, and similar items, in the radiator system mass estimates. Tables 4.2 through 4.7 provide the results of these calculations.

Based on these studies, it can be seen that significant increases in system reliability can be achieved with relatively small increases in the total number of pumped loops and masses. Furthermore, it is observed that the benefit of adding redundant pumped loops quickly reaches an asymptotic value. A beneficial consequence of this is that the eventual system designer can choose from a broad range of fabric material thickness without significantly affecting the heat rejection system mass. It is believed that such choices will then translate into reduced development and construction costs, as the designer is allowed to choose from existing commercial stocks. Table 4.8 provides a mass estimate for a pumped-loop system in which it is assumed that three individual pumped loops share a common isolation valve, and a loss of any one loop results in the loss of the others. The coupling of three 
TABLE 4.2. Effects of System Reliability on Pumped-Loop Redundancy and System Mass, Case 1 [helium/xenon pumped loop, flow area $1.0 \times 10^{-3} \mathrm{~m}^{2}$, channel length $10 \mathrm{~m}$, required number of loops at end-of-life (EOL) 93 , unarmored mass $\left.=35.9 \mathrm{~kg}^{(\cdot)}\right]$

\begin{tabular}{|c|c|c|c|}
\hline $\begin{array}{l}\text { Probability } \\
\text { of Survival }\end{array}$ & $\begin{array}{c}\text { Total Number } \\
\text { of Loops } \\
\end{array}$ & $\begin{array}{l}\text { Total Radjator } \\
\text { Mass, kg }\end{array}$ & $\begin{array}{l}\text { 2x Projected Surface } \\
\text { Area, } \mathrm{m}^{2} \\
\end{array}$ \\
\hline 0.95 & 123 & 162.9 & 88.3 \\
\hline 0.98 & 124 & 166.5 & 89.0 \\
\hline 0.99 & 125 & 169.0 & 89.7 \\
\hline 0.999 & 128 & 176.0 & 91.9 \\
\hline
\end{tabular}

TABLE 4.3. Effects of System Reliability on Pumped-Loop Redundancy and System Maşs, Case 2 (helium/xenon pumped loop, flow area $1.0 \times 10^{-3} \mathrm{~m}^{2}$, channel length $20 \mathrm{~m}$, required number of loops at EOL 43, unarmored mass $=33.2 \mathrm{~kg}^{(\mathrm{a})}$ )

\begin{tabular}{|c|c|c|c|}
\hline $\begin{array}{l}\text { Probability } \\
\text { of Survival }\end{array}$ & $\begin{array}{c}\text { Total Number } \\
\text { of Loops } \\
\end{array}$ & $\begin{array}{l}\text { Total Radjator } \\
\text { Mass, kg }\end{array}$ & $\begin{array}{c}\text { 2x Projected Surface } \\
\text { Area, } \mathrm{m}^{2}\end{array}$ \\
\hline 0.95 & 58 & 189.6 & 84.0 \\
\hline 0.98 & 59 & 195.9 & 85.4 \\
\hline 0.99 & 60 & 200.1 & 86.9 \\
\hline 0.999 & 62 & 212.5 & 89.7 \\
\hline
\end{tabular}

TABLE 4.4. Effects of System Reliability on Pumped-Loop Redundancy and System Mass, Case 3 (helium/xenon pumped loop, flow area $4.91 \times 10^{-4} \mathrm{~m}^{2}$, channel length $10 \mathrm{~m}$, required number of loops at EOL 125, unarmored mass $\left.=32.9 \mathrm{~kg}^{(2)}\right)$

\begin{tabular}{|c|c|c|c|}
\hline $\begin{array}{l}\text { Probability } \\
\text { of Survival }\end{array}$ & $\begin{array}{l}\text { Total Number } \\
\text { of Loops } \\
\end{array}$ & $\begin{array}{l}\text { Total Radjator } \\
\text { Mass, kg }\end{array}$ & $\begin{array}{l}\text { 2x Projected Surface } \\
\text { Area, } \mathrm{m}^{2} \\
\end{array}$ \\
\hline 0.95 & 164 & 138.2 & 82.5 \\
\hline 0.98 & 165 & 140.8 & 83.0 \\
\hline 0.99 & 166 & 142.6 & 83.5 \\
\hline 0.999 & 170 & 147.5 & 85.5 \\
\hline
\end{tabular}

(a) From Table 3.2

(b) Radiator mass includes liner and fabric structure/armor only. Does not include inlet or outlet headers or isolation equipment. 
IABLE 4.5. Effects of System Reliability on Pumped-Loop Redundancy and System Mass, fase 4 (helium/xenon pumped loop, flow area $4.91 \times 10^{-3} \mathrm{~m}^{2}$, channel length $20 \mathrm{~m}$, required number of loops at EOL 59, unarmored mass $=31.1 \mathrm{~kg}^{(3)}$ )

\begin{tabular}{|c|c|c|c|}
\hline $\begin{array}{l}\text { Probability } \\
\text { of Survival } \\
\end{array}$ & $\begin{array}{l}\text { Total Number } \\
\text { of Loops } \\
\end{array}$ & $\begin{array}{l}\text { Total Radjafor } \\
\text { Mass, kg }\end{array}$ & $\begin{array}{c}\text { 2x Projected Surface } \\
\text { Area, } \mathrm{m}^{2} \\
\end{array}$ \\
\hline 0.95 & 79 & 162.8 & 80.0 \\
\hline 0.98 & 80 & 167.3 & 81.0 \\
\hline 0.99 & 81 & 170.4 & 82.0 \\
\hline 0.999 & 83 & 179.4 & 84.0 \\
\hline
\end{tabular}

TABLE 4.6. Effects of System Reliability on Pumped-Loop Redundancy and System Mass, Gase 5 (helium/xenon pumped loop, flow area $7.85 \times 10^{-5} \mathrm{~m}^{2}$, channel length $10 \mathrm{~m}$ required number of loops at EOL 291, unármored mass $=29.9 \mathrm{~kg}$ a)

\begin{tabular}{|c|c|c|c|}
\hline $\begin{array}{l}\text { Probability } \\
\text { of Survival }\end{array}$ & $\begin{array}{l}\text { Total Number } \\
\text { of Loops } \\
\end{array}$ & $\begin{array}{l}\text { Total Radjafor } \\
\text { Mass, } \mathrm{kg} \text { (6) } \\
\end{array}$ & $\begin{array}{l}\text { 2x Projected Surface } \\
\text { Area, } \mathrm{m}^{2} \\
\end{array}$ \\
\hline 0.95 & 372 & 98.6 & 74.6 \\
\hline 0.98 & 375 & 99.8 & 75.2 \\
\hline 0.99 & 377 & 100.6 & 75.6 \\
\hline 0.999 & 383 & 102.9 & 76.8 \\
\hline
\end{tabular}

TABLE 4.7. Effects of System Reliability on Pumped-Loop Redundancy and System Mass, fase 6 (helium/xenon pumped loop, flow area $7.85 \times 10^{-5} \mathrm{~m}^{2}$, channel length $20 \mathrm{~m}$ required number of loops at EOL 134 unarmored mass $=27.6 \mathrm{~kg}^{(h)}$ )

Probability
of Survival

0.95

0.98

0.99

0.999

$\begin{gathered}\text { Total Number } \\ \text { of Loops }\end{gathered}$
175

175

177

178

180
Total Radjafor
Mass, kg

111.4

113.5

114.8

118.8 2x Projected Surface
Area, $\mathrm{m}^{2}$

70.4

71.2

71.6

72.4

(a) From Table 3.2

(b) Radiator mass includes liner and fabric structure/armor only. Does not include inlet or outlet headers or isolation equipment. 
TABLE 4.8. System Mass Estimate of Helium/Xenon Pumped Loop with Three Pumped Loops Sharing a Common Isolation Valve (system reliability 0.999)

\begin{tabular}{|c|c|c|c|c|c|}
\hline Case & Cross Sęction, & $\begin{array}{l}\text { No. of Loops } \\
\text { at EOL }\end{array}$ & $\begin{array}{l}\text { No. of Logps } \\
\text { at BOL }\end{array}$ & $\begin{array}{l}\text { Radiator } \\
\text { Mass, } \mathrm{kg}^{(b)} \\
\end{array}$ & $\begin{array}{l}2 x \text { Projected } \\
\text { Area, } m^{2} \\
\end{array}$ \\
\hline 1 & $1 \times 10^{-3}$ & 31 & 46 & 204.9 & 100.4 \\
\hline 2 & $1 \times 10^{-3}$ & 14 & 22 & 257.45 & 98.3 \\
\hline 3 & $4.91 \times 10^{-4}$ & 42 & 60 & 170.2 & 91.5 \\
\hline 4 & $4.91 \times 10^{-4}$ & 20 & 30 & 218.7 & 93.0 \\
\hline 5 & $7.85 \times 10^{-5}$ & 97 & 132 & 113.4 & 79.8 \\
\hline 6 & $7.85 \times 10^{-5}$ & 45 & 64 & 136.3 & 78.0 \\
\hline
\end{tabular}

\footnotetext{
(a) Beginning-of-life

(b) Radiator mass includes metallic liner and fabric structure/armor only. Does not include inlet or outlet headers or isolation equipment.
}

individual pumped loops into a common isolation valve then results in a 40 to 60\% increase in the mass of the pumped loop panels to ensure an adequate degree of survivability.

\subsection{HEAT PIPE SURVIVABILITY CALCULATIONS}

During this study, it was postulated that the development of fabric composite materials might also be applicable to conventional heat pipe systems by reducing the weight penalty associated with traditional monolithic metal armors, such as titanium. To study the effects of this substitution of armor materials, two heat pipe systems were examined.

In Case 1, a heat pipe system was chosen based on a Dowtherm- $A^{R}$ working fluid operating at $452 \mathrm{~K}$, with a heat rejection load of $79.9 \mathrm{~kW}$. Each heat pipe is assumed to be $2.5 \mathrm{~cm}$ in diameter and $5 \mathrm{~m} \mathrm{long}$, and to have a surface emissivity of 0.6 . In Calculation $A$, the heat pipe is made of titanium. In Calculation $B$, the heat pipe is constructed of a fabric material with a titanium liner and fabric wick. In each calculation, the internal configuration of the heat pipe includes a 400 -mesh wick, $0.1 \mathrm{~cm}$ thick, with eight arteries $0.1 \mathrm{~cm}$ RDowtherm-A is a heat transfer agent manufactured by Dow Chemical Co., Midland, Michigan. 
in diameter. Each heat pipe is estimated to carry $0.353 \mathrm{~kW}$, which, in turn, requires the system to contain 226 working heat pipes at EOL. To ensure an overall system reliability of 0.99 , the minimum mass system will contain approximately $7 \%$ redundant heat pipes.

In Case 2, a heat pipe system was chosen based on current SP-100 requirements. For this system, the working fluid is potassium operating at $800 \mathrm{~K}$. Total heat rejection load requirements are estimated to be approximately 2.2 MW. Each heat pipe is assumed to be $2.5 \mathrm{~cm}$ in diameter and $5 \mathrm{~m}$ long, and to have a surface emissivity of 0.6. In Calculation $A$, the heat pipe is made of titanium. In Calculation $B$, the heat pipe is made of a fabric with a titanium liner and a metallic coated fiber wick. In each calculation, the internal configuration of the heat pipe includes a 400 -mesh wick, $0.1 \mathrm{~cm}$ thick, with five arteries $0.1 \mathrm{~cm}$ in diameter. Each heat pipe is estimated to carry 3.49 $\mathrm{kW}$, which then requires the heat rejection sytsem to contain 630 working heat pipes at EOL. To ensure an overall system reliability of 0.99 , the minimum mass system will contain approximately 202 redundant heat pipes.

The results of these calculations are provided in Table 4.9. Based on these, it is expected that the use of fabric composite materials for replacement of traditional metal components offers significant mass savings to existing heat pipes, namely, a mass reduction of about $75^{\circ}$. It should be noted that, although the heat pipe configurations studied here are not optimal, it is believed that a ratio of titanium to fabric radiator masses will not be greatly affected by optimization. 
TABLE 4.9. System Mass Estimate for Postulated Heat Pipe Systems as a Function of Structural Material (system reliability 0.99 , operational lifetime 10 years)

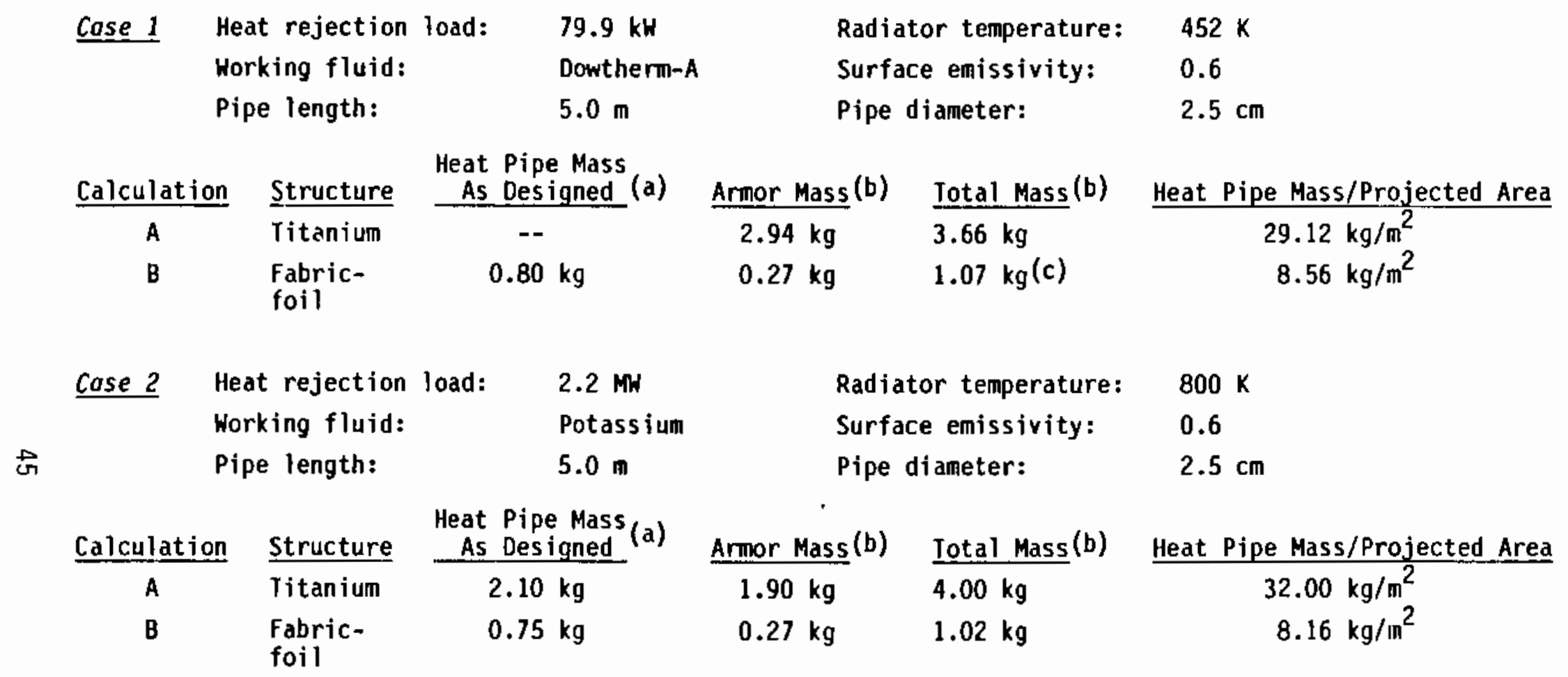

(a) As calculated in Table 3.3

(b) Mass per heat pipe

(c) Indicates over design 


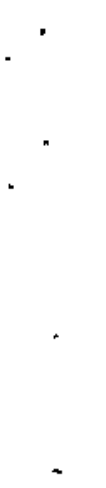




\subsection{RADIATDR OPERATION}

A successful radiator design must not only work well during steady-state operation, but must also be able to adjust to varying conditions. These include startup/shutdown, as well as transients of all degrees of severity.

\subsection{STARTUP/TRANSIENTS/SHUTDOWN}

Although each radiator concept would have some unique aspects, a general approach to transients can be developed. All radiators would be stowed in a compact configuration for launch. Deployment would occur after spacecraft insertion into orbit. Heat pipes would most likely deploy and expand solely from vapor pressure forces (Ponnappan, Beam, and Mahefkey 1986). The pumped loops might deploy solely from pump-generated pressure heads, or might require additional mechanical aids (e.g., such as currently used to deploy spacecraft booms and antennae). The presence of mechanical devices would serve the additional function of permitting radiator shape alteration at will.

Startup should be simplified by the flexible nature of the proposed radiator design. That is, the long heat paths present in more conventional radiator designs are inherently avoided by the stowed, flexible radiators. As for transients, these again are more readily sumounted by the proposed designs. Variations in heat load could be adjusted to in several ways: for the heat pipe radiator, a higher temperature/pressure operating point is readily achievable given the inherent tensile strength of the fabric containment at high temperature. Similar comments hold for the pumped loops. The most severe possible transient (due to a laser threat) would require a hardened design. Such is certainly within reason, with minimal mass penalty. Lower heat fluxes could be handled either by lowering the radiator temperature or by retracting a suitable portion of the radiator area.

Shutdown, if it becomes necessary, could be the reverse of the startup scenario. Mechanical reels or other retraction devices could stow nonoperating radiators, reducing drag on the spacecraft while simultaneously making it more difficult to track. The details of a planned shutdown operation have not been addressed here. 


\subsection{SHAPE ALTERATION}

A unique feature of flexible radiators is the inherent ability to alter the shape of the radiator in radical ways. This freedom opens up many possibilities. The signature of the spacecraft could be altered to make identification more difficult. Threats could be countered by stowing, retracting, or otherwise moving the threatened radiator panels; new panels could be unfurled to replace damaged ones and/or change the radiator shape. 


\subsection{FEASIBILITY ISSUES}

In this section, the key technical issues are described. As with any new technology, numerous issues have been identified here that inhibit the imnediate application of fabric radiators.

\subsection{KEY TECHNICAL ISSUES IDENTIFIED}

These issues are listed in Table 6.1, as well as relevant comments regarding their current status and anticipated resolution.

\subsection{TECHNICAL ISSUES OUTSTANDING}

Among the issues shown in Table 6.1, several are crucial to development of a fabric radiator technology base. Survivability, retention of long-term flexibility, and long-term compatibility with the working fluid are the chief issues that must be resolved to establish the validity of the proposed radiator

\section{TABLE 6.1. Key Technical Issues}

\begin{tabular}{|c|c|}
\hline Issue & Status \\
\hline Flexibility & Demonstrated \\
\hline Survivability & Not demonstrated \\
\hline Mass & $\begin{array}{l}\text { Low mass potential } \\
\text { demonstrated analytically }\end{array}$ \\
\hline Compatibility & Not demonstrated \\
\hline Bonding & Demonstrated \\
\hline Startup & Not demonstrated \\
\hline Performance & Demonstrated analytically \\
\hline $\begin{array}{l}\text { Emittance/ } \\
\text { transmittance }\end{array}$ & Measured \\
\hline
\end{tabular}

Comments

Needs to be explored more

Must be demonstrated for pumped loops

Low mass appears feasible

Requires selection of proper materials

Needs to be explored more and optimized

Only experiment can verify startup/deployment features

Only experiment can verify

Need to be explored more and optimized 
concept. Although we have explored these issues, definitive data are lacking. The next step in a fabric radiator development program would be to acquire such data, which would serve both to confim the claimed advantages of fabric radiators over conventional approaches and provide design and system optimization inputs. If a viable fabric radiator design is achievable, system optimization may show that the entire spacecraft is beneficially affected through incorporation of this radiator. One can envision that a power system could readily benefit from the lighter mass of a fabric radiator, permitting operation at lower heat rejection temperature and increasing power system reliability through a decreased reactor temperature. Conversely, the high-temperature potential of ceramic materials may be exploited to reduce radiator area, assuming the rest of the spacecraft's power system were not the limiting factor on the temperature.

\subsection{RECOMMENDED APPROACH}

Based on the results from this research effort, we feel that the earliest application of fabric technology could occur in heat pipes. These largely avoid the survivability issue; until that is resolved, pumped loops cannot be recommended.

It is proposed that an experimental fabric heat pipe development program be initiated. The work would encompass a number of activities: study of ceramic wick/working fluid compatibility, bonding techniques, and optimization of the ceramic wick structure and weave. If a ceramic wick is found to be incompatible for long-term use with desirable working fluids, currently available (individual) fiber coating techniques could be used to provide compatibility while retaining most of the all-ceramic wick's mass advantage (Research and Development 1987). In conjunction with these material studies, a proof-of-concept low-temperature heat pipe should be fabricated and tested. We project a 1-year program, at the end of which fabric heat pipe technology should be firmly established. 
A parallel effort, in pumped-loop fabric radiator survivability, would serve to determine if such is realistically attainable. All possible means of increasing survivability need to be explored; we have thought of many approaches, but have been unable to explore them in any detail. Some of the candidate methods are shown in Table 6.2. Note that survivability consists of hardening as well as improved methods of failure detection. If a design cannot be hardened sufficiently to be survivable, it may still be possible to generate an acceptable design. Accurate detection of the location and size of a failure point allows one to take active countermeasures to limit or repair the damage inflicted.

TABLE 6.2. Approaches for Enhancing Survivability Against Micrometeoroid Punctures

Method

\section{Sealing \\ Pinch-off \\ Sealant \\ Self-healing \\ Redundancy}

Detection

Infrared

Sonic

$\Delta \mathbf{P}$

Fluid inventory

Temperature change
Comments

Would take advantage of fabric's compliance

Problematic

Eutectic braze development required

of benefit only if isolation of punctured panels can be ensured

Very sensitive; could triangulate on leak location Might work for gases

Probably not feasible

Gross measure only

Gross measure only 


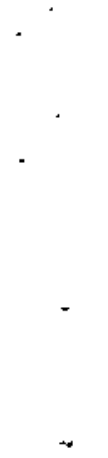

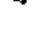




\subsection{CONCLUSIONS}

The design of large, high-temperature space radiators is still an evolving discipline. We have expanded the data base available to a designer by studying a novel class of radiators, those constructed of ceramic fabrics lined with a metal foil. It appears that fabric radiators have features not available in more conventional radiator types, while offering the light weight and stowability of advanced radiators, such as liquid droplet. Experiments performed to date show that fabrics can be treated to become impermeable to the working fluid while retaining flexibility. This inherent feature of fabrics, when allied to their low density, provides a material well-adapted to radiator construction. As study proceeds, the advantages of fabric over other radiator types will become even more evident.

A direct pumped-loop fabric radiator system offers significant mass savings over conventional radiators and even over fabric heat pipes. An indirect pumped-loop system has not been analyzed completely, and probably would not offer as great a mass saving. Both pumped-loop systems are viable only if some means is developed to ensure a high survivability. Barring that, the heat pipe system is the obvious choice, given its inherent redundancy. But a heat pipe radiator system exacts a price in terms of added complexity and mass. Determination and design of an optimized radiator system remains as a task for future endeavors. 


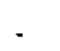




\subsection{REFERENCES}

Anonymous. 1987. "Thermoplastic Resins for EMI/RF Shielding." Research and Development, July, p. 88.

Brennan, P. J., and E. J. Kroliczek. 1979. Heat Pipe Design Handbook, Volumes 1 and 2, N81-70112/3. National Technical Information Service, Springfield, Virginia.

Carlson, K. E., P. A. Roth, and V. H. Ransom. 1986. ATHENA Code Manual 1 and 2. EGG-RTH-7397, EG\&G Idaho, Idaho Falls, Idaho.

Chi, S. W. 1976. Heat Pipe Theory and Practice. Hemisphere Publishing/ MCGraw-Hill, New York.

Chow, L. C., and E. T. Mahefkey, 1986. "Fluid Recirculation, Deployment and Retraction of an Expandable Pulse Power Radiator." Paper no. AIAA-86-1322, in Trans. AIAA/ASME 4th Joint Thermophysics and Heat Transfer Conference. American Institute of Aeronautics and Astronautics, New York, New York.

Cour-Palais, B. G. 1969. Meteoroid Environment Model--1969 (Near Earth to Lunar Surface). NASA SP-8013, NASA Space Vehicle Design Criteria (Environment), National Aeronautics and Space Administration, Houston, Texas.

Covington, M. A., and P. M. Sawko. 1986. "Optical Properties of Woven Ceramic Fabrics for Flexible Heat Shields." Paper no. AIAA-86-1281, in Trans. AIAA/ASME 4th Joint Thermophysics and Heat Transfer Conference. American Institute of Aeronautics and Astronautics, New York, New York.

Dearien, J.A., and J. F. Whitbeck. 1987. "Multimegawatt Nuclear Systems for Space Power." Paper no. 879359, in Proc. 22nd Intersociety Energy Conversion Engineering Conference, Vol. 1, pp. 468-477. American Institute of Aeronautics and Astronautics, New York, New York.

Dunn, P. D., and D. A. Reay. 1982. Heat Pipes. 3rd ed. Pergamon Press, Elmsford, New York.

Ernst, D. M. 1981. "Heat Pipes for NEP Spacecraft Radiators." Paper no. 819164, in Proceedings 16th Intersociety Energy Conversion Engineering Conference. Anerican Society of Mechanical Engineers, New York, New York.

Fareed, A. S., P. Fang, M. J. Koczak, and F. M. Ko. 1987. "Thermomechanical Properties of Silicon Carbide Yarn." Am. Ceram. Soc. Bull. 66(2):353-358.

Fraas, A. P. 1986. Protection of Spacecraft from Meteoroids and Orbital Debris. ORNL/TM-9904, Oak Ridge National Laboratory, Oak Ridge, Tennessee. 
Josloff, A. T., A. Kirpich, and R. E. Biddiscombe. 1987. "SP-100 Alternative Designs." Paper no. 879109, in Proc. 22nd Intersociety Energy Conversion Engineering Conference, Vol. 1, pp. 414-418. American Institute of Aeronautjcs and Astronautics, New York, New York.

Lundberg, A. B., S. J. Bless, S. P. Girrens, and J. F. Greens. 1982. Hypervelocity Impact Studies on Titanium, Titanium Alloys, and Beryllium. LA-9417-MS, Los ATamos National Laboratory, Los Alamos, New Mexico.

McNamara, E. J., F. A. Dottore, H. G. Larson, and A. F. Montague, Jr. 1987. "Analytical Studies Performed Supporting the SP-100 Heat Rejection Subsysten." Paper no. 879113, in Proc. 22nd Intersociety Energy Conversion Engineering Conference, Vol. 1, pp. 424-429. American Institute of Aeronautics and Astronautics, New York, New York.

Meier, K. L., S. P. Girrens, and J. M. Dickinson. 1980. "Titanium Heat Pipes for Space Power Systems." Paper no. 809144, in Proc. 15th Intersociety Energy Conversion Engineering Conference. American Institute of Aeronautics and Astronautics, New York, New York.

Merrigan, M. A., E. S. Keddy, J. T. Sena, and M. G. Elder. 1984. "Heat Pipe Technology Development for High Temperature Space Radiator Applications." Paper no. 849453, in Proc. 19th Intersociety Energy Conversion Engineering Conference, Vol. 1, pp. 592-597. American Nuclear Society, Hinsdale, Illinois.

Mock, E. A. 1977. Closed Cycle Gas Turbine Optimization--Procedure and Examples. Airesearch Report 31-2635, Airesearch Manufacturing Co., Phoenix, Arizona.

Ponnappan, R., J. E. Beam, and E. T. Mahefkey. 1986. "Conceptual Design of an $1 \mathrm{~m}$ Long 'Roll Out Fin' Type Expandable Space Radiator." In Trans. AIAA/ASME 4th Joint Thermophysics and Heat Transfer Conference. American Institute of Aeronautics and Astronautics, New York, New York.

Prenger, F. C., Jr. 1979. Heat Pipe Computer Program (HTPIPE) User's Manual. LA-8101-M, Los Alamos Scientific Laboratory, Los Alamos, New Mexico.

National Aeronautics and Space Administration. 1985. Proceedings of the Solar Maximum Repair Mission Degradation Study Workshop. NASA-TM-89274, Cleveland, Ohio.

Sawko, P. M., and H. K. Tran. 1985. "Strength and Flexibility Properties of Advanced Ceramic Fabrics." SAMPE Quarterly. 17(1):7-13.

Tai-il Mah, N. G. Mendiratta, A. P. Katz, and K. S. Mozdiyasni. 1987. "Recent Developments in Fiber-Reinforced High/ Temperature Ceramic Composites." Ceramic Bulletin. 66(2):304. 
Tilton, D. E., and L. C. Chow. 1986. "Flow Through a Pierced Membrane in a Vacuum." Paper no. AIAA-86-1324, in Trans. AIAA/ASME 4th Joint Thermophysics and Heat Transfer Conference. American Institute of Aeronautics and Astronautics, New York, New York.

Webb, B. J., and Z. I. Antoniak. 1986. "Rotating Bubble Membrane Radiator for Space Applications." Paper no. 869426, in Proc. 21st Intersociety Energy Conversion Engineering Conference, Vol. 3, pp. 1881-1885. American Chenical Society, Washington, D.C.

Weeton, J. W., D. M. Peters, and K. L. Thomas. 1987. Engineers' Guide to Composite Materials. American Society for Metals, Metals Park, Ohio. 
APPENDIX A

SAMPLE HEAT PIPE CODE RESULTS 
APPENDIX A

SAMPLE HEAT PIPE CODE RESULTS

Heat Pipe Analysis: Power Vs Tee

Total Number of Arteries

Artery Inside Radius

Artery Pumping Radius

Artery Geometry

No. of Art. Not Operating

Artery Screen Thickness

Wick Porosity

Wick Permeability

Distrib. Screen Thickness

Evaporator Length

Adiabatic Length

Condenser Length

Angle From Horizontal

Pipe Inside Radius

Working Fluid No.

Pipe Effective Length

Vapor Passage Area

Total Liquid Flow Area

Wicking Screen Thickness

Wicking Density

Metallic Liner Thickness

Metallic Liner Density

Pressure Wall Thickness

Pressure Wall Density

$$
\begin{aligned}
& =5 \\
& =\quad .50000 \mathrm{E}-01 \\
& =.31800 \mathrm{E}-02 \\
& =1 \text { Circular } \\
& =0 \\
& =\quad .30000 \mathrm{E}-01 \\
& =\quad .50000 \mathrm{E}+00 \\
& =\quad .99000 \mathrm{E}-07 \\
& =\quad .50000 \mathrm{E}-01 \\
& =\quad .40000 \mathrm{E}+02 \\
& =.10000 \mathrm{E}+02 \\
& =.50000 \mathrm{E}+03 \\
& =\quad .00000 \mathrm{E}+00 \\
& =\quad .12500 \mathrm{E}+01 \\
& =21 \text { Potassium } \\
& =.28000 \mathrm{E}+03 \\
& =.40542 \mathrm{E}+01 \\
& =\quad .39270 \mathrm{E}-01 \\
& =\quad .10000 \mathrm{E}+00 \\
& =.24000 E+01 \\
& =\quad .20000 \mathrm{E}-02 \\
& =.45000 \mathrm{E}+01 \\
& =\quad .40000 \mathrm{E}-02
\end{aligned}
$$

\begin{tabular}{|c|c|c|c|c|c|c|c|}
\hline $\begin{array}{l}\text { Tee } \\
\text { Power }\end{array}$ & $\begin{array}{r}\text { Liquid } \\
\text { Hydrostatic }\end{array}$ & $\begin{array}{l}\text {-Pressur } \\
\text { Vapor (L) } \\
\text { Vapor(T) }\end{array}$ & $\begin{array}{r}\text { Drops-a } \\
\text { Inertial } \\
\text { Capillary }\end{array}$ & $\begin{array}{l}\text { Evaporator } \\
\text { Adiabatic }\end{array}$ & $\begin{array}{r}\text { Temper } \\
\text { Tbe } \\
\text { Tbeson }\end{array}$ & $\begin{array}{l}\text { ature } \\
\text { Tbc } \\
\text { Tbcson }\end{array}$ & $\begin{array}{l}\text { Limits } \\
\text { Qsonic } \\
\text { Qentrn }\end{array}$ \\
\hline $\begin{array}{r}650 \\
-2687\end{array}$ & $\begin{array}{r}8603 . \\
0 .\end{array}$ & $\begin{array}{r}0 \\
27530\end{array}$ & $\begin{array}{l}47639 . \\
55579 .\end{array}$ & $\begin{array}{l}49679 \\
-2024 \\
-680\end{array}$ & $\begin{array}{l}795 . \\
677 .\end{array}$ & $\begin{array}{l}674 . \\
637 .\end{array}$ & $\begin{array}{l}602 . \\
4925 .\end{array}$ \\
\hline $\begin{array}{r}670 \\
-3264\end{array}$ & $\begin{array}{r}10115 \\
0\end{array}$ & $\begin{array}{r}0 \\
24979\end{array}$ & $\begin{array}{l}45476 . \\
54748 .\end{array}$ & $\begin{array}{l}47326 \\
-2165 \\
-528\end{array}$ & $\begin{array}{l}795 . \\
701 .\end{array}$ & $\begin{array}{l}690 . \\
659 .\end{array}$ & $\begin{array}{l}959 . \\
6077 .\end{array}$ \\
\hline $\begin{array}{r}690 \\
-3910\end{array}$ & $\begin{array}{r}11767 \\
0\end{array}$ & $\begin{array}{r}0 . \\
22771\end{array}$ & $\begin{array}{l}43452 . \\
53918 .\end{array}$ & $\begin{array}{r}45138 \\
-2570 \\
-417\end{array}$ & $\begin{array}{l}796 . \\
724 .\end{array}$ & $\begin{array}{l}709 . \\
680 .\end{array}$ & $\begin{array}{l}1482 \\
7389\end{array}$ \\
\hline
\end{tabular}




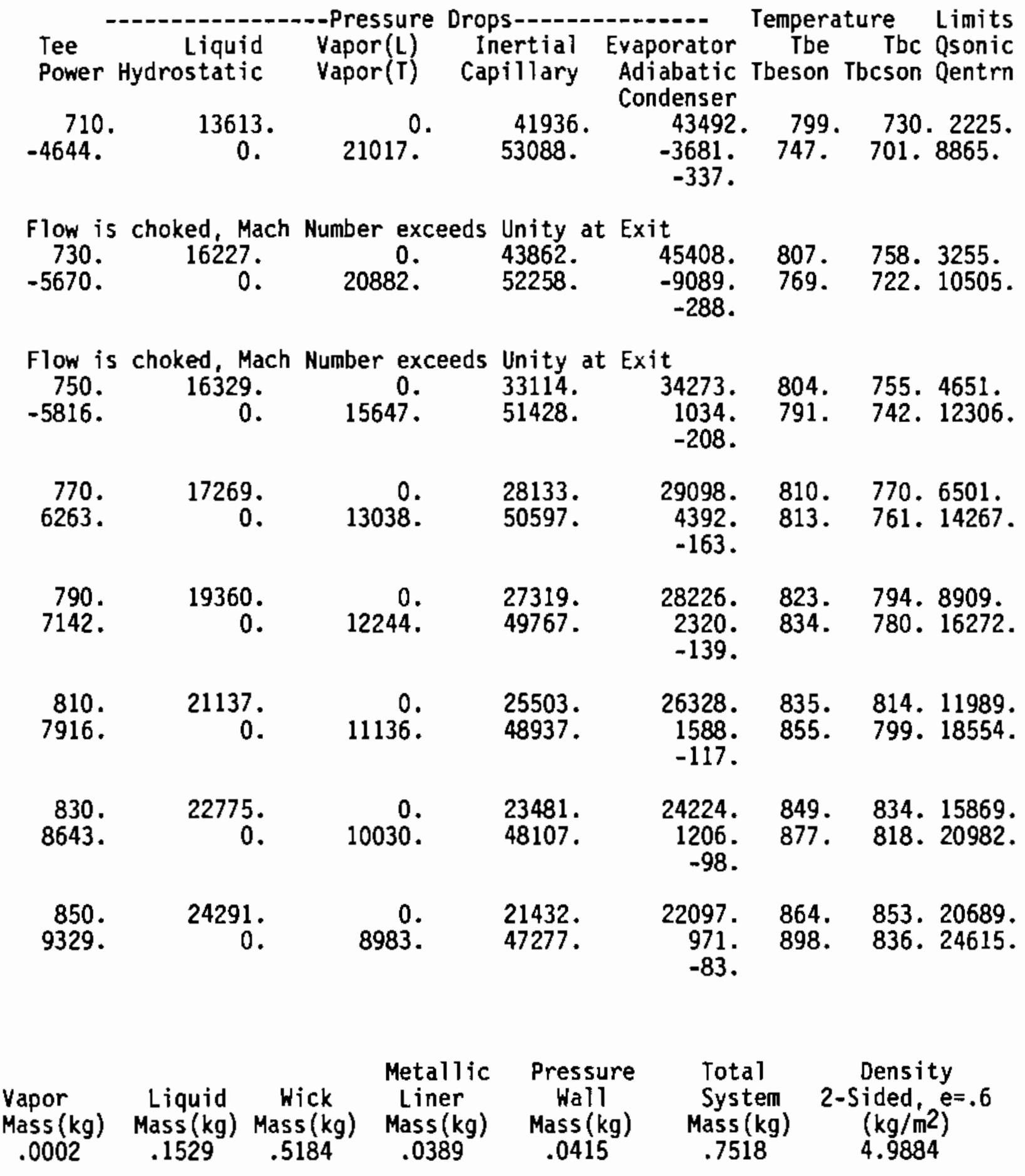


Heat Pipe Analysis: Power Vs Tee

Total Number of Arteries

Artery Inside Radius

Artery Pumping Radius

Artery Geometry

No. of Art. Not Operating

Artery Screen Thickness

Wick Porosity

Wick Permeability

Distrib. Screen Thickness

Evaporator Length

Adiabatic Length

Condenser Length

Angle From Horizontal

Pipe Inside Radius

Working Fluid No.

Pipe Effective Length

Vapor Passage Area

Total Liquid Flow Area

Wicking Screen Thickness

Wicking Density

Metallic Liner Thickness

Metallic Liner Density

Pressure Wall Thickness

Pressure Wall Density

$$
\begin{aligned}
& =5 \\
& =\quad .50000 E-01 \\
& =\quad .31800 E-02 \\
& \text { = } 1 \text { Circular } \\
& =0 \\
& =\quad .30000 \mathrm{E}-01 \\
& =\quad .50000 \mathrm{E}+00 \\
& =\quad .99000 \mathrm{E}-07 \\
& =\quad .50000 E-01 \\
& =\quad .40000 \mathrm{E}+02 \\
& =\quad .10000 \mathrm{E}+02 \\
& =.50000 E+03 \\
& =\quad .00000 E+00 \\
& =.12500 \mathrm{E}+01 \\
& =21 \text { Potassium } \\
& =.28000 \mathrm{E}+03 \\
& =.40542 E+01 \\
& =\quad .39270 \mathrm{E}-01 \\
& =\quad .10000 \mathrm{E}+00 \\
& =\quad .45000 \mathrm{E}+01 \\
& =\quad .25000 \mathrm{E}-01 \\
& =.45000 E+01 \\
& =\quad .25000 \mathrm{E}-01 \\
& =.45000 \mathrm{E}+01
\end{aligned}
$$

\begin{tabular}{|c|c|c|c|c|c|c|c|}
\hline $\begin{array}{l}\text { Tee } \\
\text { Power }\end{array}$ & $\begin{array}{r}\text { Liquid } \\
\text { Hydrostatic }\end{array}$ & $\begin{array}{l}\text {-Pressure } \\
\text { Vapor }(\mathrm{L}) \\
\text { Vapor }(\mathrm{T})\end{array}$ & $\begin{array}{l}\text { Drops- } \\
\text { Inertial } \\
\text { Capillary }\end{array}$ & $\begin{array}{l}\text { Evaporator } \\
\text { Adiabatic } \\
\text { Condenser }\end{array}$ & $\begin{array}{r}\text { Temper } \\
\text { Tbe } \\
\text { Tbeson }\end{array}$ & $\begin{array}{l}\text { ature } \\
\text { Tbc } \\
\text { Tbcson }\end{array}$ & $\begin{array}{l}\text { Limits } \\
\text { Qsonic } \\
\text { Qentrn }\end{array}$ \\
\hline $\begin{array}{r}650 . \\
-2687 .\end{array}$ & $\begin{array}{r}8603 . \\
0 .\end{array}$ & $\begin{array}{r}0 \\
27530\end{array}$ & $\begin{array}{l}47639 \\
55579\end{array}$ & $\begin{array}{l}49679 \\
-2024 \\
-680\end{array}$ & $\begin{array}{l}795 . \\
677 .\end{array}$ & $\begin{array}{l}674 \\
637\end{array}$ & $\begin{array}{l}602 . \\
4925 .\end{array}$ \\
\hline $\begin{array}{r}670 \\
-3264\end{array}$ & $\begin{array}{r}10115 . \\
0 .\end{array}$ & $\begin{array}{r}0 \\
24979\end{array}$ & $\begin{array}{l}45476 \\
54748\end{array}$ & $\begin{array}{l}47326 \\
-2165 \\
-528\end{array}$ & $\begin{array}{l}795 . \\
701 .\end{array}$ & $\begin{array}{l}690 . \\
659 .\end{array}$ & $\begin{array}{l}959 \\
6077 .\end{array}$ \\
\hline $\begin{array}{r}690 \\
-3910\end{array}$ & $\begin{array}{r}11767 \\
0\end{array}$ & $\begin{array}{r}0 \\
22771\end{array}$ & $\begin{array}{l}43452 . \\
53918 .\end{array}$ & $\begin{array}{l}45138 \\
-2570 \\
-417\end{array}$ & $\begin{array}{l}796 . \\
724 .\end{array}$ & $\begin{array}{l}709 . \\
680 .\end{array}$ & $\begin{array}{l}1482 . \\
7389 .\end{array}$ \\
\hline $\begin{array}{r}710 \\
-4644\end{array}$ & $\begin{array}{r}13613 \\
0\end{array}$ & $\begin{array}{r}0 \\
21017\end{array}$ & $\begin{array}{l}41936 . \\
53088 .\end{array}$ & $\begin{array}{c}43492 \\
-3681 \\
-337\end{array}$ & $\begin{array}{l}799 . \\
747 .\end{array}$ & $\begin{array}{l}730 . \\
701 .\end{array}$ & $\begin{array}{l}2225 . \\
8865 .\end{array}$ \\
\hline
\end{tabular}




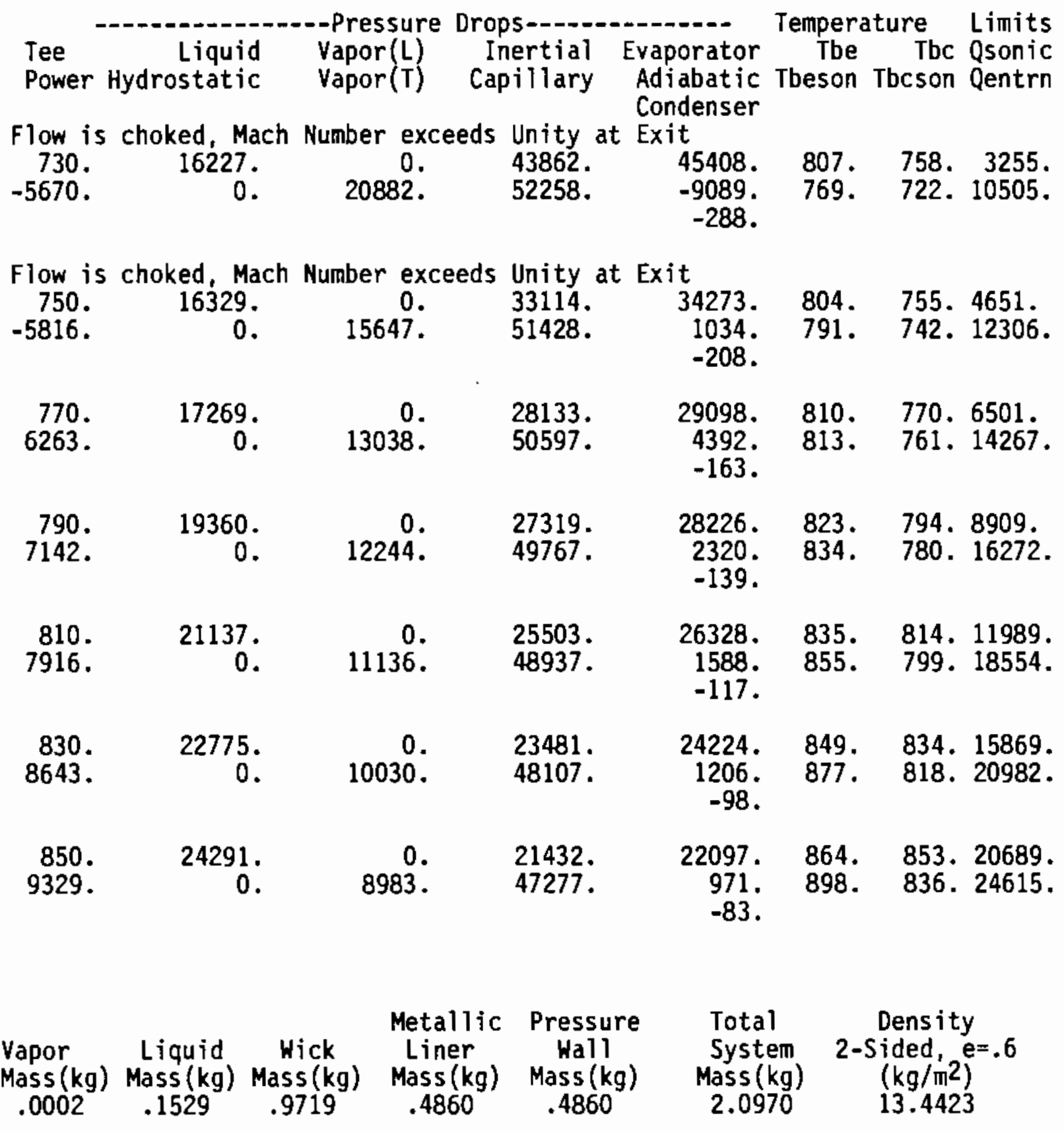


APPENDIX B

SURVIVABILITY PROGRAM LISTING 
APPENDIX B

\section{SURVIVABILITY PROGRAM LISTING}

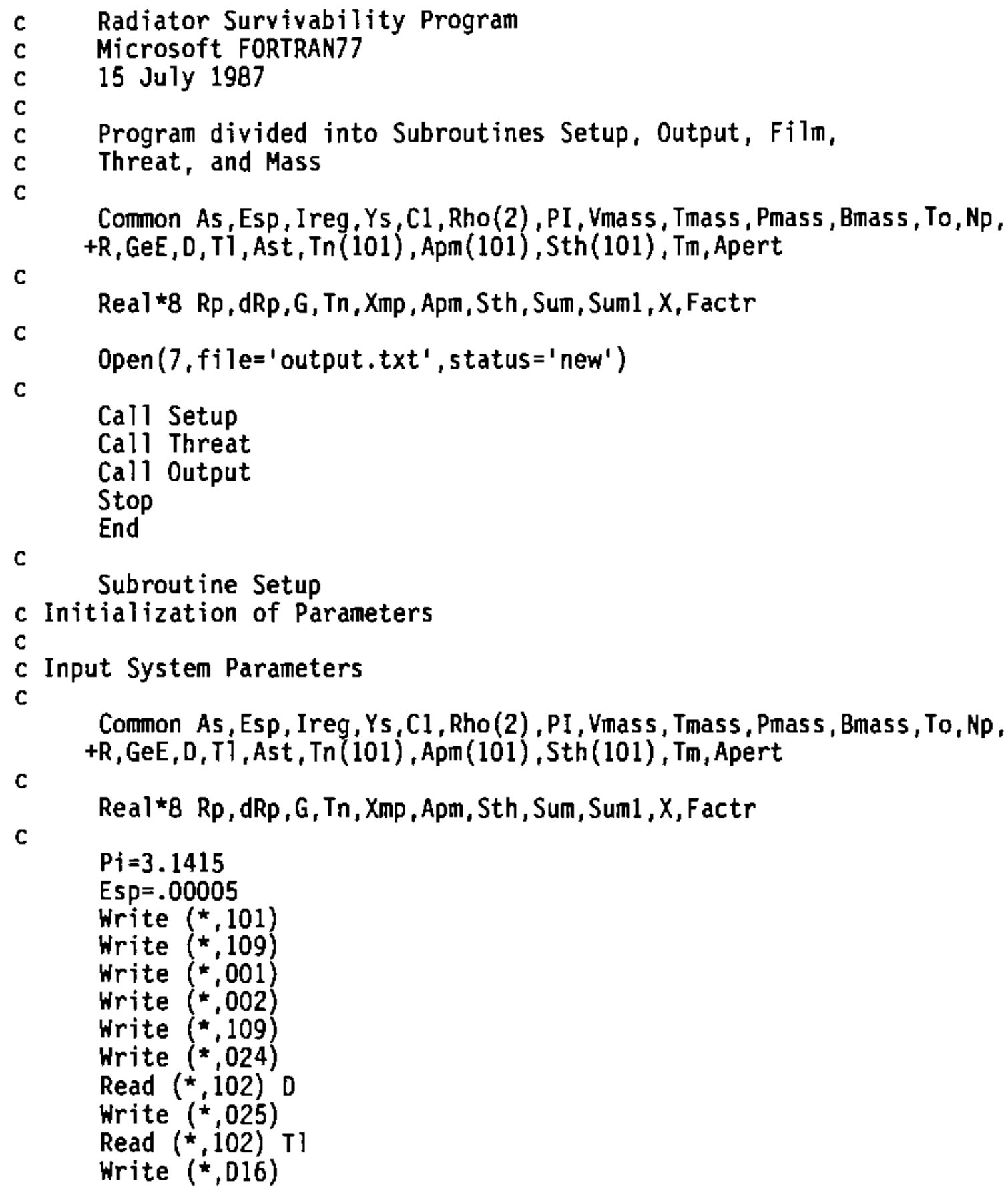




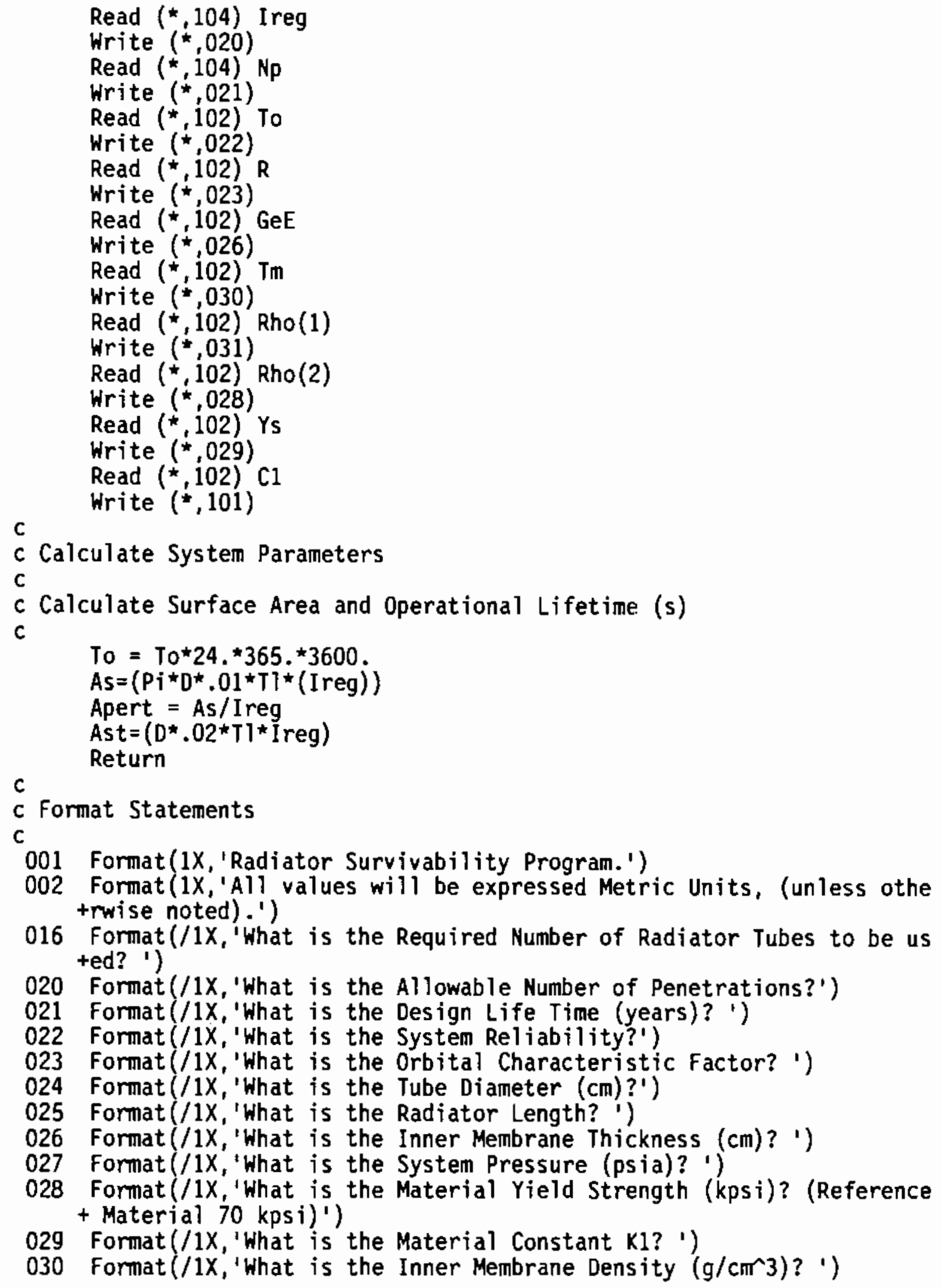




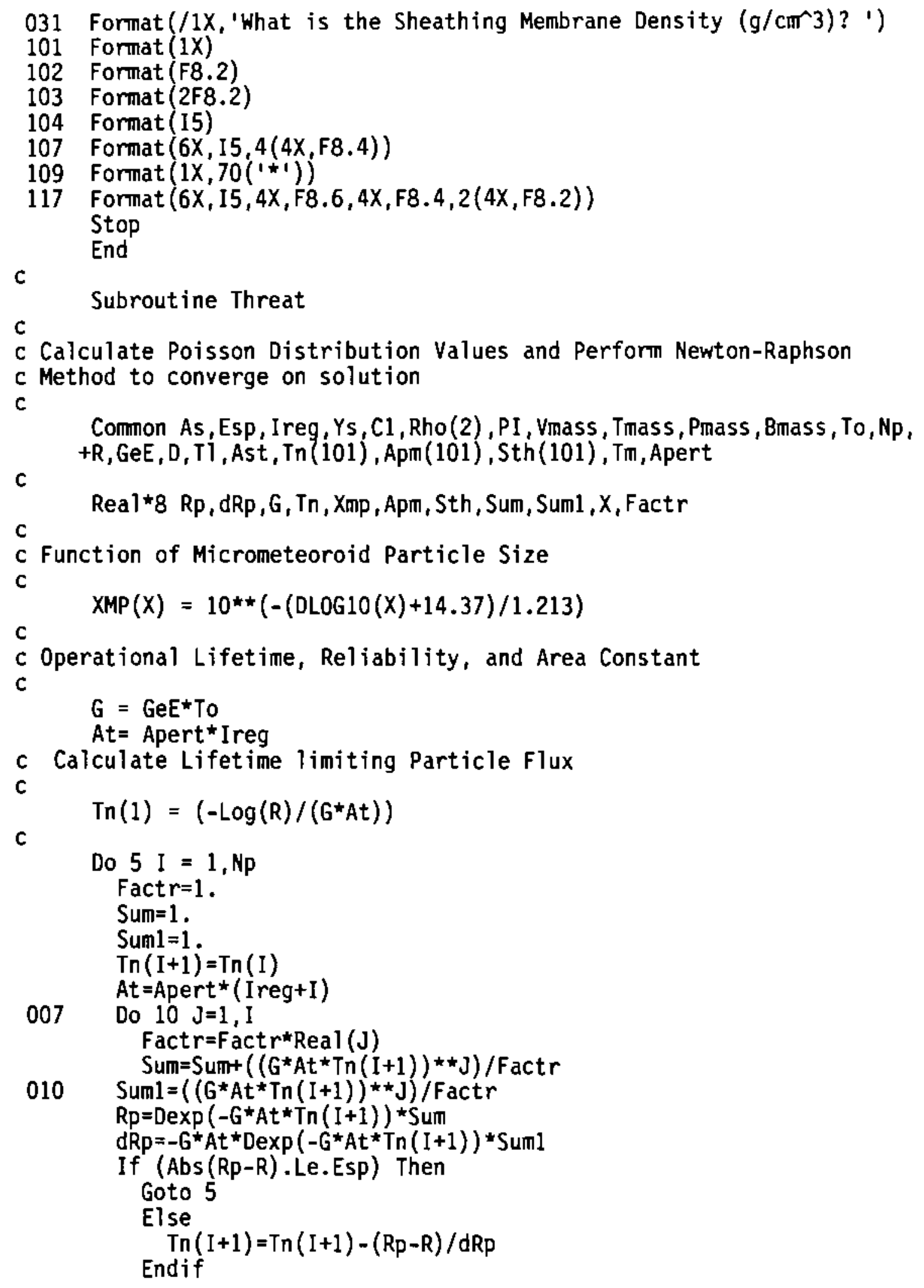

Real*8 Rp, dRp, G, Tn, Xmp , Apm, Sth , Sum, Suml , X, Factr

c Function of Micrometeoroid Particle Size

$\operatorname{XMP}(X)=10^{\star \star}(-(\operatorname{DLOG} 10(X)+14.37) / 1.213)$

c Operational Lifetime, Reliability, and Area Constant

$G=G e E^{\star} T_{0}$

At $=$ Apert ${ }^{\star}$ Ireg

c Calculate Lifetime limiting Particle flux

C

C

$$
\operatorname{Tn}(1)=\left(-\log (R) /\left(G^{\star} A t\right)\right)
$$

Do $5 \mathrm{I}=1, \mathrm{~Np}$

Factr $=1$.

Sum $=1$.

Suml $1=1$.

$\operatorname{Tn}(I+1)=\operatorname{Tn}(I)$

At $=$ Apert* $($ Ireg +1$)$

007 Do $10 \mathrm{~J}=1, \mathrm{I}$

Fact $r=F$ actr*Real $(\mathrm{J})$

Sum $=$ Sum $+\left(\left(G^{\star} A t^{\star} \operatorname{Tn}(I+1)\right){ }^{\star \star J}\right) /$ Factr

010 Sum $1=\left(\left(G^{*} A t^{*} \operatorname{Tn}(I+1)\right)^{\star \star} \mathrm{J}\right) /$ Factr

$R p=\operatorname{Dexp}\left(-G^{\star} A t \star \operatorname{Tn}(I+1)\right) \star S u m$

$\operatorname{dR} p=-G^{\star} A t * \operatorname{Dexp}\left(-G^{\star} A t^{\star} \operatorname{Tn}(I+1)\right) *$ Suml

If (Abs (Rp-R).Le.Esp) Then

Goto 5

Else

$\operatorname{Tn}(I+1)=\operatorname{Tn}(I+1)-(R p-R) / d R p$ Endif

C

C

c

c 


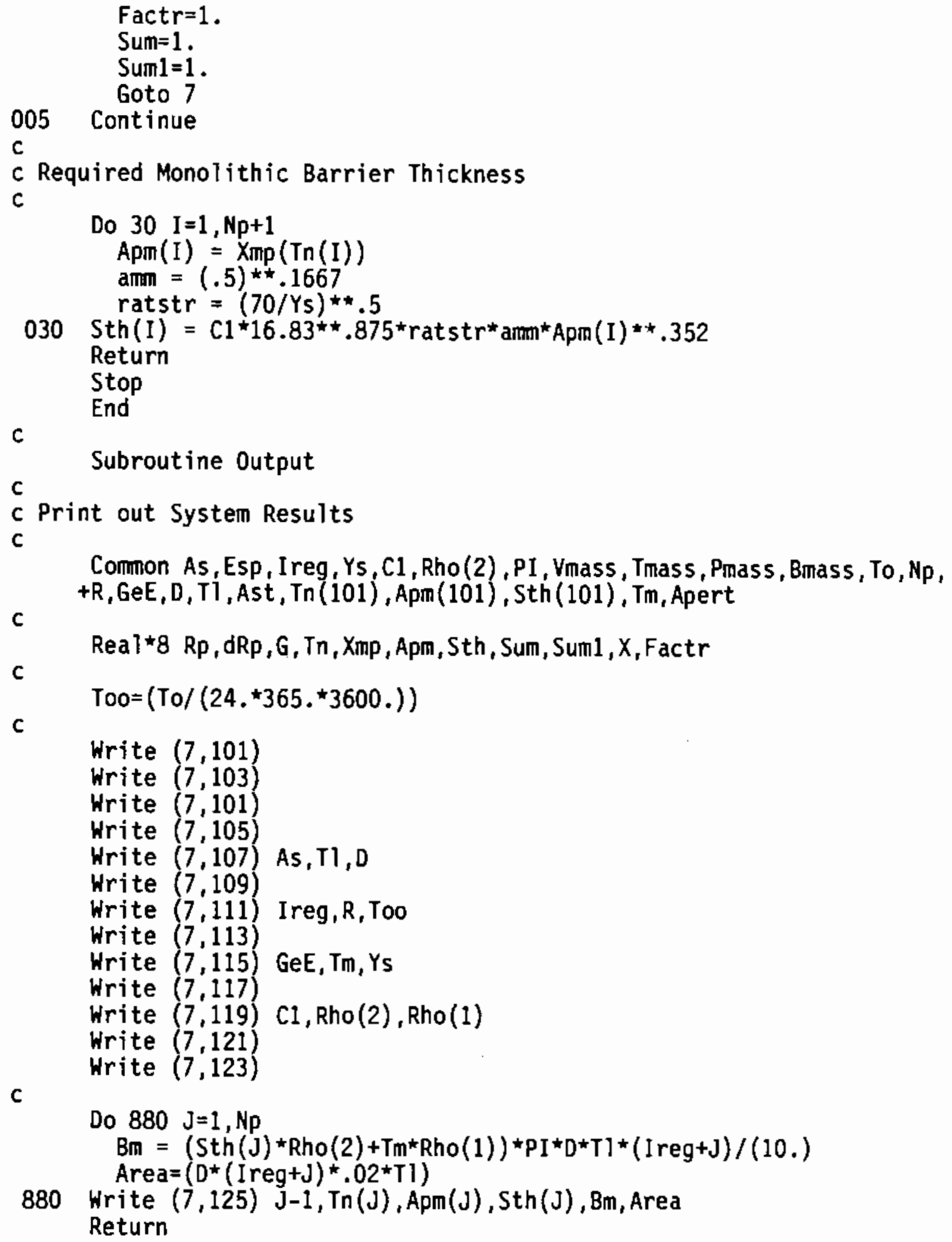




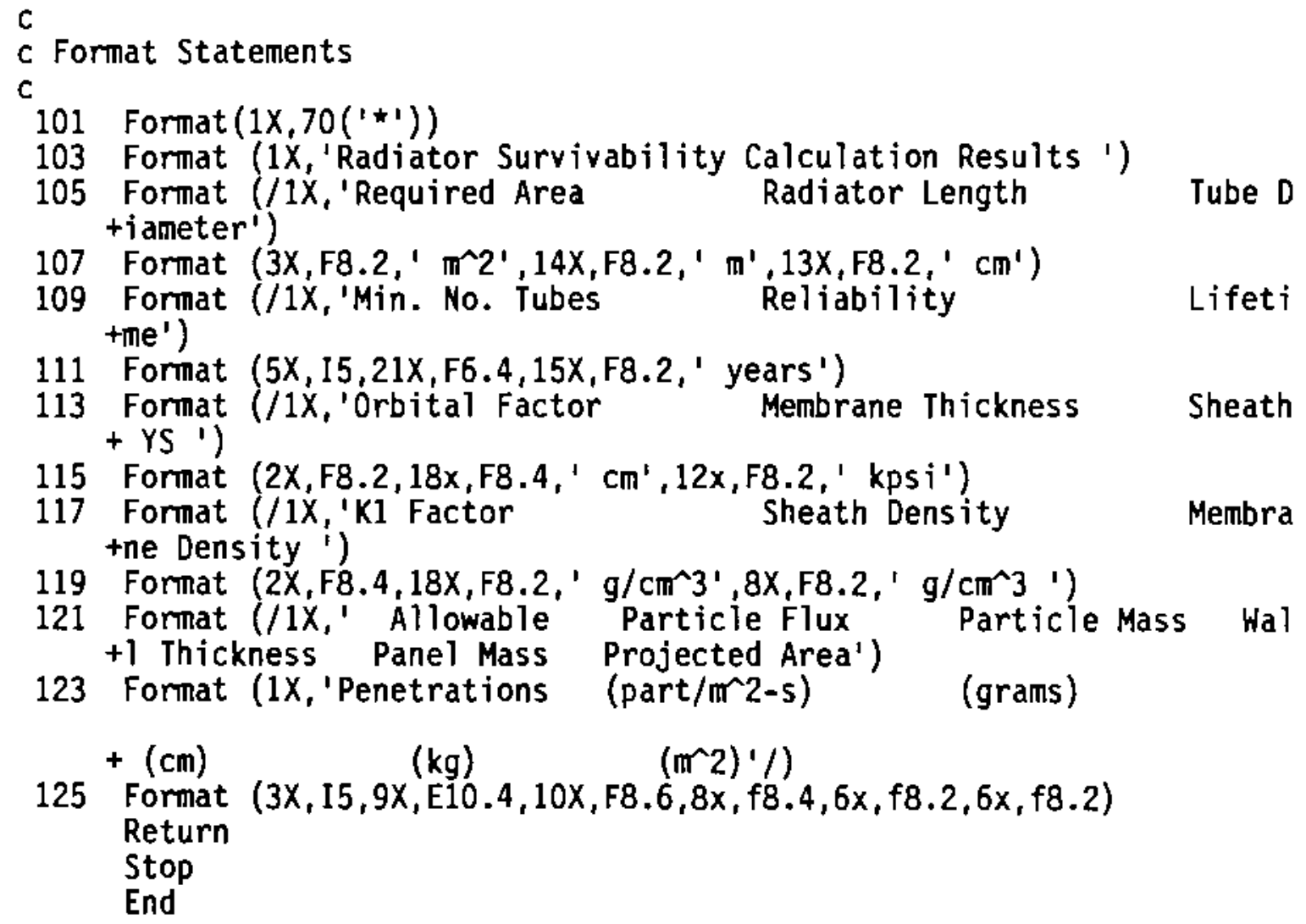




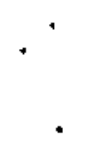

. 


\section{DISTRIBUTION}

No. of

Copies

OFFSITE

10 DOE Office of Scientific and Technical Information

S. G. Bankoff

Chem. Eng. Dept.

Northwestern Univ.

Evanston, IL 60208

C. R. Bell

Los Alamos National Laboratory

P0 Box 1663

Los Alamos, NM 87545

D. R. Bennett

Department of Energy (LANL)

NE/521 Germantown

Washington, DC 20545

S. K. Bhattacharyya

Argonne National Laboratory

$9700 \mathrm{~S}$. Cass B1dg. 207

Argonne, IL 60439

J. B. Blackmon

McDonnell. Douglas Astronautics

5301 Bolsa Avenue

Huntington Beach, CA 92647

R. J. Bohl

Los Alamos National Laboratory

P0 Box 1663

Los Alamos, MN 87545

D. W. Chaudoir

Sundstrand Energy Systems

4747 Harrison Avenue

PO Box 7002

Rockford, IL 61125-7002

J. W. H. Chi

Westinghouse Electric Corp.

Waltz Mill Site

Madison, PA 15663-0158
No. of

Copies

P. T. Choong

Rasor Associates, Inc.

253 Humboldt Court

Sunnyvale, CA 94089

H. E. Collicott

MS 82-23, P0 Box 3999

Boeing Aerospace Co.

Seattle, WA 98124

R. H. Cooper

Oak Ridge National Laboratory

PO Box $X$

Oak Ridge, TN 37831

J. L. Crews

NASA/JSC/SW 12

Houston, TX 77058

Louis 0. Cropp

Sandia National Laboratory

Box 5800

Albuquerque, NM 87185

Dick Dahlberg

GA Technologies Inc.

PO Box 85608

San Diego, CA 92138-5608

J. J. Der

MS4/964

Aerospace Corporation

PO Box 92957

Los Angeles, CA 90009-2957

P. J. Dirkmaat

Department of Energy

Idaho Operations office

785 DOE Place

Idaho Falls, ID 83402

J. R. Distefano

Martin Marietta Energy Systems

PO Box $X, B] d g$. 4500S

0ak Ridge, TN 37831-6157 
No, of

Copies

A. E. Dukler

University of Houston

Department of Chemical Eng. 4800 Calhoun

Houston, TX 77004

G. 0. Fitzpatrick

GA Technologies Inc.

PO Box 85608

San Diego, CA 92138-5608

B. B. Gillies

ETEC/Rockwell International

PO Box 1449

Canoga Park, CA 91304

D. Gray

Department of Civil Engineering

West Virginia University

Morgantown, WV 26506-6101

S. L. Gretzkowski

McDonnell Douglas Astronautics

5301 Bolsa Avenue

Huntington Beach, CA 92647

R. D. Hahn

U.S. Department of Energy

DP-22.2 Germantown

Washington, DC 20545

J. K. Hartman

1333 Broadway Avenue

0akland, CA 94612

E. E. Hoffiman

U.S. Department of Energy

Oak Ridge Operations Office

Federal Bldg.

Oak Ridge, TN 37830

H. W. Hoffman

Department of Energy

Oak Ridge Operations Office

PO Box X

Oak Ridge, TN 37830
No. of

Copies

R. L. Holton

Department of Energy

A]buquerque Operations office PO Box 5400

Albuquerque, NM 87115

J. L. Hooper

Department of Energy

Chicago Operations Office

$9800 \mathrm{~S}$. Cass Avenue

Argonne, IL 60439

J. F. Kespein

PMN-144-251

Space and Naval Warfare

System Command

Washington, DC 20301

E. Khan

BDN Corp.

7915 Jones Branch Road

McLean, VA 22071

A. C. Klein

Oregon State University

Department of Nuclear Eng.

Corvallis, OR 97331

J. N. Koster

Engineering Center, ECOT 5-7

Campus Box 432

University of Colorado

Boulder, CO 80309-0432

W. J. Krotiuk

Astro Space Division

MS 410-2-A18

PO Box 800

Princeton, NJ 08543-0800

M. L. Kuka

McDonnell Douglas Astronautics

5301 Bolsa Avenue

Huntington Beach, CA 92647 
No. of

Copies

W. E. Lambert

Department of Energy

SAN Operations office

1333 Broadway

0akland, CA 94612

Major R. Lenard

SDI Office/KE

The Pentagon/2E 261

Washington, DC 20301

V. Lo

STI

2755 Northup Way

Bellevue, WA 98004

R. Long

NASA Johnson Space Center

Code EC2

Houston, TX 77058

H. Ludewig

Brookhaven National Laboratory

Upton, Long Is land, NY 11973

E. T. Mahefkey

AFWAL/POOS-3

Wright-Patterson AFB, $\mathrm{OH}$ 45433-6563

D. R. McVay United Technologies Power Systems 185 Governors Highway

PO Box 109

South Windsor, CT 06074

M. A. Merrigan

Los Alamos National Laboratory

P0 Box 1663

Los Alamos, NM 87544

H. Merte, Jr.

University of Michigan

Department of Mechanical

Engineering and Applied Mechanics

2250 G. G. Brown

Ann Arbor, MI 48109-2125
No. of

Copies

J. S. Meserole

Boeing Aerospace Co.

PO Box 3999

Seattle, WA 98124

W. Nesmith

Jet Propulsion Laboratory

4800 Oak Grove Drive

Pasadena, CA 91109

N. R. Ortiz

Sandia National Laboratory

P0 Box 5800

Albuquerque, NM 87185

E. Normand

Boeing Aerospace Co.

P0 Box 3999, MS 87-60

Seattle, WA 98124

R. Parrish

Code EC2

NASA Johnson Space Center

Building 7A Room 122

Houston, TX 77058

K. L. Peddicord

Department of Nuclear Eng.

Texas A\&M University

College Station, TX 77843

R. E. Pepping

Sandia National Laboratories

Advanced Power Systems

Division 6511

ATbuquerque, NM 87185

J. R. Powell

Brookhaven National Laboratory

Upton, NY 11973

J. L. Preston, Jr.

United Technologies Power Systems

185 Governors Highway

PO Box 109

South Windsor, CT 06074 
No. of

Copies

E. D. Rossel

L-Garde, Inc.

15181 Woodlawn Avenue

Tustin, CA 92680

J. A. Salzman

NASA Lewis Research Center

21000 Brookpark Road

Cleveland, $\mathrm{OH} \quad 44135$

J. F. Santarius

Fusion Technology Institute

University of Wisconsin

1500 Johnson Drive

Madison, WI 53706-1687

A. Schor

Massachusetts Institute of Technology

Department of Nuclear Eng.

Room 24-215

Cambridge, MA 02139

R. K. Sievers

Westinghouse Electric Corp. Waltz Mill Site

Madison, PA 15663-0158

N. F . Shepard, Jr.

General Electric Co.

PO Box 8555

Philadelphia, PA 19101

L. K. Slimak

AFRPL/DYS/STOP 24

Air Force Rocket Propulsion Laboratory

Edwards AFB, CA 93523

R. J. Sovie

NASA Lewis Research Center

21000 Brookpark Road

Cleveland, $\mathrm{OH} 44135$

G. Stapher

Jet Propulsion Laboratory

4800 0ak Grove Drive

Pasadena, CA 91109
No, of

Copies

A. M. Sutey

Boeing Aerospace Co.

P0 Box 3999, MS 8K-30

Seattle, WA 98124-2499

F. V. Thome

Sandia National Laboratory

P0 Box 5800

Albuquerque, NM 87185

V. Truscello

Jet Propulsion Laboratory

4800 0ak Grove Drive

Pasadena, CA 91109

E. Van Landingham

NASA Headquarters

Code RD

Washington, DC 20546

R. L. Verga

SDI office/SLKT

The Pentagon Building

Washington, DC 20301

R. W. Vernon

NASA Lewis Research Center

21000 Brookpark Road

Cleveland, $\mathrm{OH} 44135$

E. J. Wahlquist

Department of Energy

Headquarters

NE/521 Germantown

Washington, DC 20545

C. E. Walter

Lawrence Livermore National Laboratory

PO Box 808

Livermore, CA 94550

J. W. Warren

U.S. Department of Energy

Washington, DC 20585 
No. of

Copies

J. R. Wetch

Space Power Inc.

1977 Concourse Drive

San Jose, CA 95131

R. L. Wiley

SDI Office/SLKT

The Pentagon

1717 H St., N.W.

Washington, DC 20301

K. A. Williams

Science Applications

International Corp.

2109 Air Park Road S.E.

Albuquerque, NM 87106

C. Zweben

General Electric Co.

B100/M4018

P0 Box 8555

Philadelphia, PA 19101

\section{$\underline{\text { ONSITE }}$}

4 DOE Richland Operations Office

K. R. Absher (3)

J. J. Sutey

2 Hanford Engineering Development Laboratory

D. S. Dutt

A. Padilla
No. of

Copies

80 Pacific Northwest Laboratory

Z. I. Antoniak (30)

J. M. Bates

J. 0. Barner

D. B. Cearlock

T. T. Claudson

E. P. Coomes (10)

J. M. Cuta

B. M. Johnson

J. T. Prater

L. C. Schmid

C. W. Stewart

R. A. Stokes

D. S. Trent

B. J. Webb (20)

R. D. Widrig

N. D. Wogman

Technical Report Files (5)

Publishing Coordination (2) 


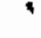

